\title{
COMBINED IN-PLANE AND THROUGH-THE-THICKNESS ANALYSIS FOR FAILURE PREDICTION OF BOLTED COMPOSITE JOINTS
}

\author{
V. Kradinov, ${ }^{*}$ E. Madenci ${ }^{\dagger}$ \\ The University of Arizona, Tucson, Arizona, 85715 \\ D. R. Ambur \\ NASA Langley Research Center, Hampton, Virginia, 23681
}

\begin{abstract}
$\underline{\text { Abstract }}$
Although two-dimensional methods provide accurate predictions of contact stresses and bolt load distribution in bolted composite joints with multiple bolts, they fail to capture the effect of thickness on the strength prediction. Typically, the plies close to the interface of laminates are expected to be the most highly loaded, due to bolt deformation, and they are usually the first to fail. This study presents an analysis method to account for the variation of stresses in the thickness direction by augmenting a two-dimensional analysis with a onedimensional through the thickness analysis. The twodimensional in-plane solution method based on the combined complex potential and variational formulation satisfies the equilibrium equations exactly, and satisfies the boundary conditions and constraints by minimizing the total potential. Under general loading conditions, this method addresses multiple bolt configurations without requiring symmetry conditions while accounting for the contact phenomenon and the interaction among the bolts explicitly. The through-thethickness analysis is based on the model utilizing a beam on an elastic foundation. The bolt, represented as a short beam while accounting for bending and shear deformations, rests on springs, where the spring coefficients represent the resistance of the composite laminate to bolt deformation. The combined in-plane and through-the-thickness analysis produces the bolt/ hole displacement in the thickness direction, as well as the stress state in each ply. The initial ply failure predicted by applying the average stress criterion is followed by a simple progressive failure. Application of the model is demonstrated by considering single- and double-lap joints of metal plates bolted to composite laminates.
\end{abstract}

\footnotetext{
*Technical Expert, Department of Aerospace and Mechanical Engineering.

${ }^{\dagger}$ Professor, Department of Aerospace and Mechanical Engineering. Member AIAA.

$\$$ Head, Mechanics and Durability Branch. Associate Fellow AIAA.

Copyright (C) 2004 by the American Institute of Aeronautics and Astronautics. All rights reserved.
}

\section{Introduction}

Bolts provide the primary means of connecting composite parts in the construction of aircraft and aerospace vehicles. The main disadvantage of bolted joints is the formation of high stress concentration zones at the locations of bolt holes, which might lead to a premature failure of the joint due to net-section, shear-out, or bearing failures, or their combinations. The stress state in a bolted joint is dependent on the loading conditions, dimensions, laminate stacking sequence, bolt clamp-up forces, bolt location, bolt flexibility, bolt size, and bolthole clearance (or interference). A substantial number of experimental, analytical, and numerical investigations have been conducted on the stress analysis of bolted laminates. The study by Kradinov et al. ${ }^{1}$ provides an extensive and detailed discussion of earlier investigations. In order to eliminate the shortcomings of the previous analyses, Kradinov et al. introduced a twodimensional numerical/analytical method to determine the bolt load distribution in bolted single- and doublelap composite joints utilizing the complex potentialvariational formulation. This method addresses multiple bolt configurations without requiring symmetry conditions while accounting for the contact phenomenon and the interaction among the bolts explicitly under bearing and by-pass loading. The contact stresses and contact regions are determined through an iterative procedure as part of the solution method.

Although this two-dimensional approach provides an accurate prediction of the contact stresses and bolt load distribution, it fails to capture the effect of thickness on the failure prediction. In addition to the head and nut shapes and the applied bolt torque, the stacking sequence considerably influences the stress state in each ply of the laminate. Thus, an adequate representation of the ply load variation through the thickness is critical for the failure prediction of composite laminates at the bolt-hole boundary.

This study presents an analysis method to account for the variation of stresses in the thickness direction by augmenting the two-dimensional analysis by Kradinov et al. ${ }^{1}$ with a model of a bolt on an elastic foundation, as suggested by Ramkumar et al. ${ }^{2}$ The bolt, represented as a beam while accounting for bending and shear deformations, rests on springs, where the spring coefficients 
represent the resistance of the composite laminate to bolt deformations. The values of the spring coefficients depend on the fiber orientation of the laminate plies; for isotropic plates, the spring coefficients are defined by a constant value. The present analysis produces the bolt/ hole displacement in the thickness direction and the stress state in each ply. Failure load and associated failure modes of net-section, bearing, and shear-out for composite bolted joints are predicted based on the average stress criterion of Whitney and Nuismer ${ }^{3}$ for first ply failure, followed by a simple progressive failure criterion as suggested by Ramkumar et al. ${ }^{2}$

The applicability of this method is demonstrated by considering single- and double-lap joints of laminates with a varying number of bolts. In addition to the determination of the contact stresses and the bolt load distributions, the failure load is investigated by applying a progressive failure procedure based on the average stress failure criterion.

\section{Problem Statement}

The geometry of bolted single- and double-lap joints of composite laminates is described in Fig. 1. Each joint can be subjected to a combination of bearing, by-pass, and shear loads. Each laminate of the single- and double-lap joints, joined with $L$ number of bolts, can be subjected to tractions and displacement constraints along its external boundary. The thickness of the laminates is denoted by $h_{k}$. As illustrated in Fig. 2, the hole radius in the $k^{\text {th }}$ laminate associated with the $\ell^{\text {th }}$ bolt, $a_{k, \ell}$ (which is slightly larger than the bolt radius, $R_{\ell}$ ), leads to a clearance of $\delta_{k, \ell}$. The ranges of the subscripts are specified by $k=1, \ldots, K$ and $\ell=1, \ldots, L$, with $K$ and $L$ being the total number of laminates and bolts, respectively. The bolt radius remains the same in each laminate; however, the radii of the holes associated with the same bolt are not necessarily the same.

The extent of the contact region is dependent on the bolt displacement deformation of the hole boundary, and the clearance. The presence of friction between the bolts and the laminates is disregarded. Each laminate with a symmetric lay-up of $N_{k}$ plies can have distinct anisotropic material properties. Each bolt can also have a distinct stiffness, and the explicit expressions for bolt stiffness for a single- and double-lap joint, as well as the general lap configurations, are derived in Kradinov et al. ${ }^{1}$

The problem posed concerns the determination of the extent of the contact zones, the contact stresses and the bolt load distribution under general loading conditions, the bolt/hole deformation, and the stress state in each ply, and thus the joint strength.
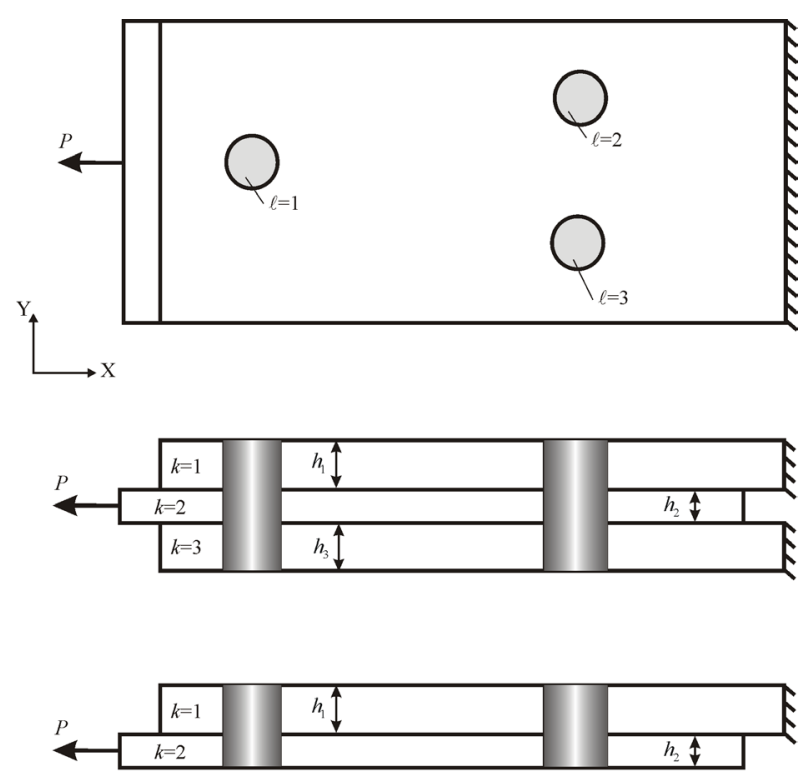

$\stackrel{ }{\mathrm{Z}} \longrightarrow \mathrm{X}$

Fig. 1 Geometric description of single- and doublelap bolted joints.

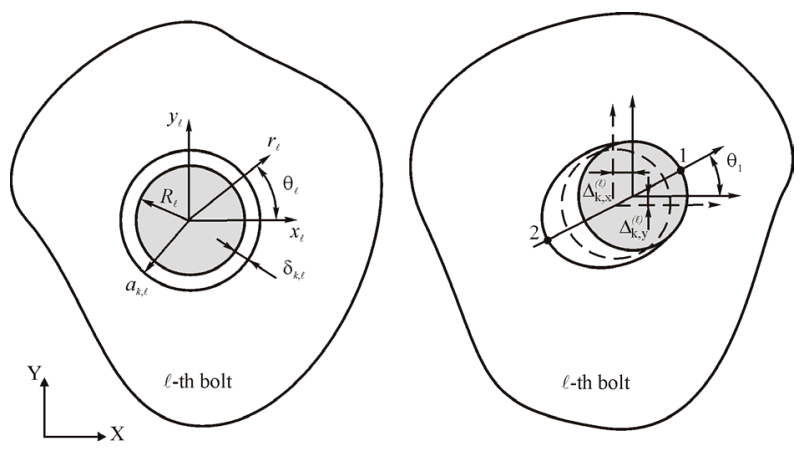

Fig. 2 Position of a bolt before and after the load is exerted.

\section{Solution Method}

In-Plane Analysis for Contact Stresses and Bolt Load Distribution

The coupled complex potential and variational formulation introduced by Kradinov et al. ${ }^{1,4}$ is employed to determine the two-dimensional stress and strain fields required for the computation of the contact stresses and contact regions, as well as the bolt load distribution. This in-plane analysis is capable of accounting for finite laminate planform dimensions, uniform and variable laminate thickness, laminate lay-up, interaction among bolts, bolt torque, bolt flexibility, bolt size, bolt-hole clearance and interference, insert dimensions, and insert material properties. Unlike the finite 
element method, it alleviates the extensive and expensive computations arising from the non-linear nature of the contact phenomenon. Also, the method is more suitable for parametric study and design optimization.

Although this two-dimensional analysis provides accurate in-plane stresses in each laminate and bolt load distribution, it assumes no variation of stresses through the laminate thickness. This assumption might lead to erroneous results in the strength prediction of bolted joints because of the pronounced influence of throughthe-thickness stress variation at the bolt location as discussed by Ramkumar et al. ${ }^{2}$

\section{Through-Thickness Analysis for Bolt/Hole Deformation}

In conjunction with a two-dimensional in-plane bolted joint analysis, Ramkumar et al. ${ }^{2}$ suggested a model utilizing a beam on an elastic foundation in order to include the variation of stresses in the thickness direction of the bolted joint. The bolt rests on springs, where the spring constants represent the resistance of the laminate to bolt deformation. The spring constants correspond to the modulus of each ply through the thickness of the hole boundary. Their values depend on the ply orientation of the laminate. For isotropic plates, the spring constants have a uniform value.

As the bolt bends, the plies are loaded differently near the hole boundary based on their orientation and location. As shown in Fig. 3, the plies close to the interface of adjacent laminates exhibit significant deformation. As shown in Fig. 4, the beam representing the bolt rests on an elastic foundation whose modulus is represented by the stiffness of each ply, $k_{k, i}^{(\ell)}$, in the laminate. The superscript $\ell$ and subscripts $k$ and $i$ denote the specific bolt, the laminate, and the ply numbers, respectively. Also, the bolt is subjected to constraints at the head and nut locations through rotational stiffness constants, $k_{h}^{(\ell)}$ and $k_{n}^{(\ell)}$, in order to include the effect of head and nut shapes and bolt torque.

Free-body diagrams of the laminates at the $\ell^{\text {th }}$ bolt in a single- and double-lap joint and the end conditions

(a)

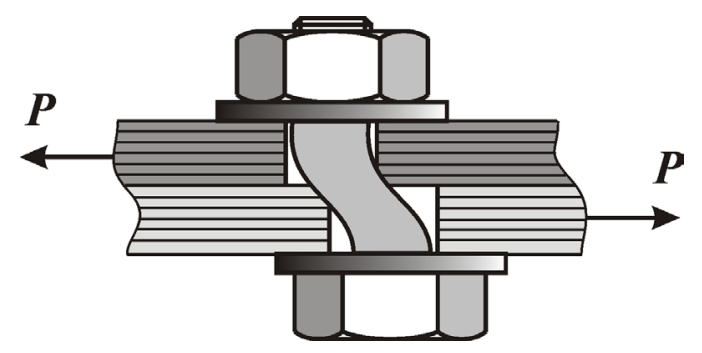

and slope continuity conditions in the presence of both bending and shear deformations are shown in Fig. 5. In accordance with the typical bolt deformation illustrated in Fig. 3, the force exerted by the $\ell^{\text {th }}$ bolt on the $k^{\text {th }}$ laminate, $P_{k}^{(\ell)}$ (obtained from the two-dimensional inplane analysis), is enforced as a shear force, $V_{k}^{(\ell)}$, at the interface of the adjacent laminates. At the interface, the continuity of the bending slopes, $\psi_{k}^{(\ell)}=\psi_{k+1}^{(\ell)}$, is also enforced while permitting the laminates to displace. At the head and nut locations of the bolt, the shear force values are set to zero, and the rotations (slopes) are dictated by rotational stiffness constants, $k_{h}^{(\ell)}$ and $k_{n}^{(\ell)}$, depending on the bolt type, presence of washers, and the applied bolt torque.

Finite Element Analysis. The bolt/hole displacements through the laminate thickness are obtained by discretizing the bolt with beam elements that account for bending and shear deformations. The bolt discretization is based on the discrete nature of the ply stacking sequence. Along its thickness, each ply is discretized with two beam elements. For both single- and doublelap joints, the number of elements and the number of nodes in relation to the number of plies in the laminate are described in Fig. 6. In the discretization process, a node located in the middle of each ply is attached to a spring element representing the ply stiffness (Fig. 6).

The derivation of the stiffness matrix composed of a two-noded beam element (Timoshenko's zeroth-order shear deformable beam theory) and a linear spring element is presented in the Appendix.

Associated with the $k^{\text {th }}$ laminate and the $\ell^{\text {th }}$ bolt, each node is assigned a deflection, $\Delta_{k, j}^{(\ell)}=\Delta_{k}^{(\ell)}\left(z_{j}\right)$, and a rotation, $\phi_{k, j}^{(\ell)}=\phi_{k}^{(\ell)}\left(z_{j}\right)$, with the subscript $j$ representing the node number. In the finite element formulation, the rotations of the internal nodes are statically condensed in terms of the nodal displacements and the end node rotations. The positive directions of the deflections and rotations are shown in Fig. 7. The details of the condensation procedure are also explained in the Appendix.

(b)

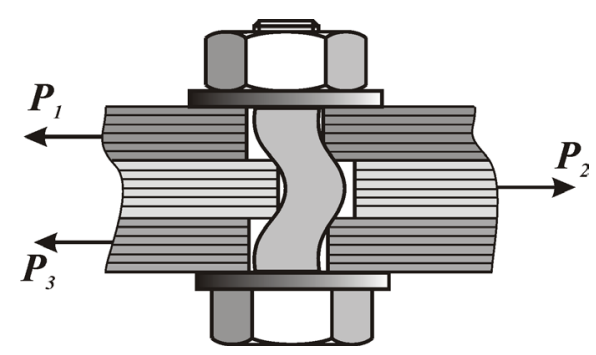

Fig. 3 Typical bolt deformation in a (a) single- and (b) double-lap joint. 


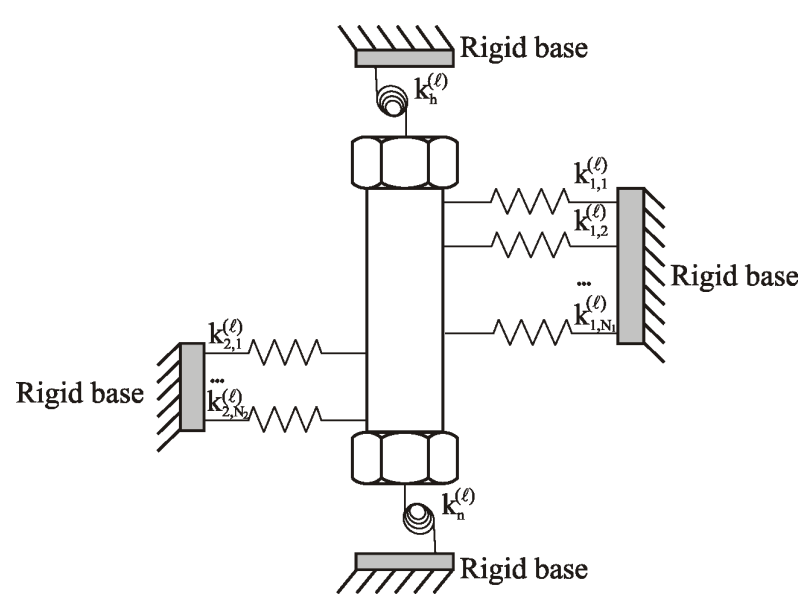

(a)

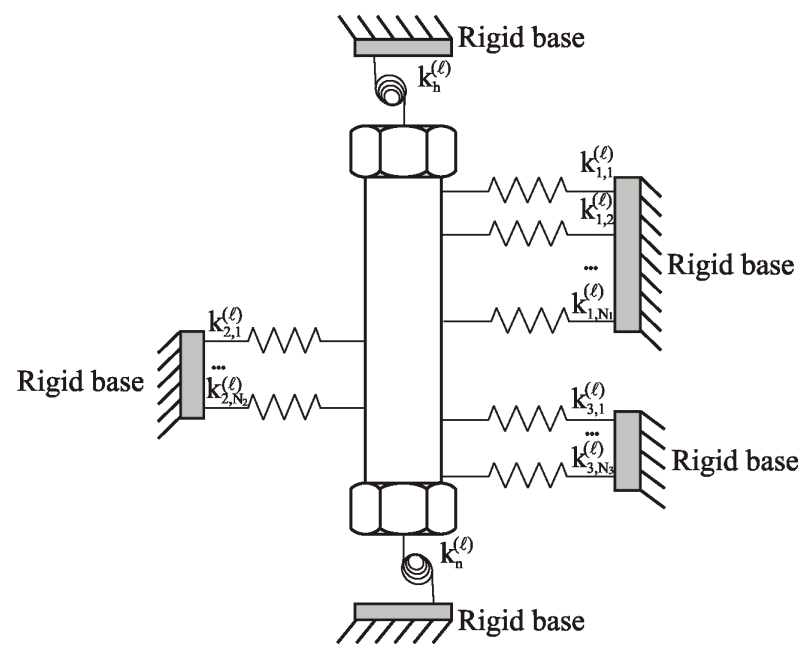

(b)

Fig. 4 Bolt on an elastic foundation model in a (a) single- and (b) double-lap joint.

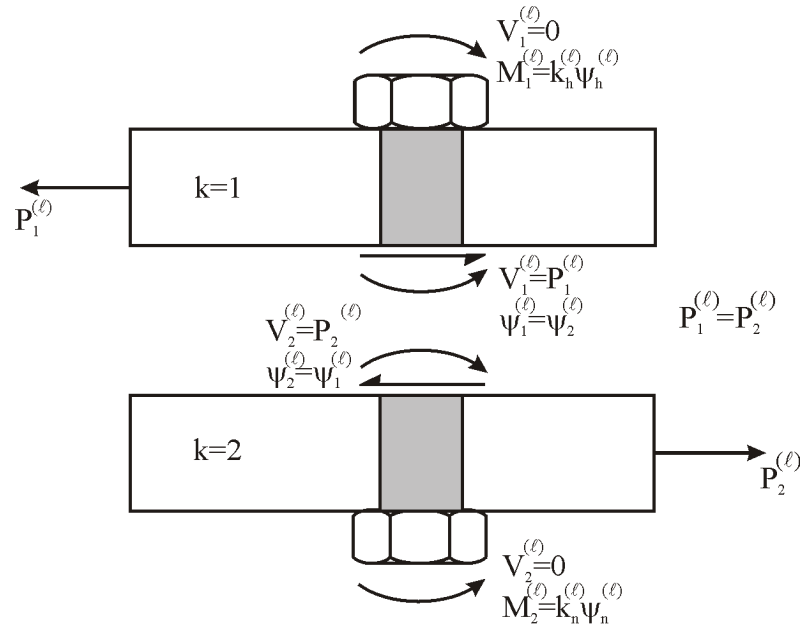

(a)

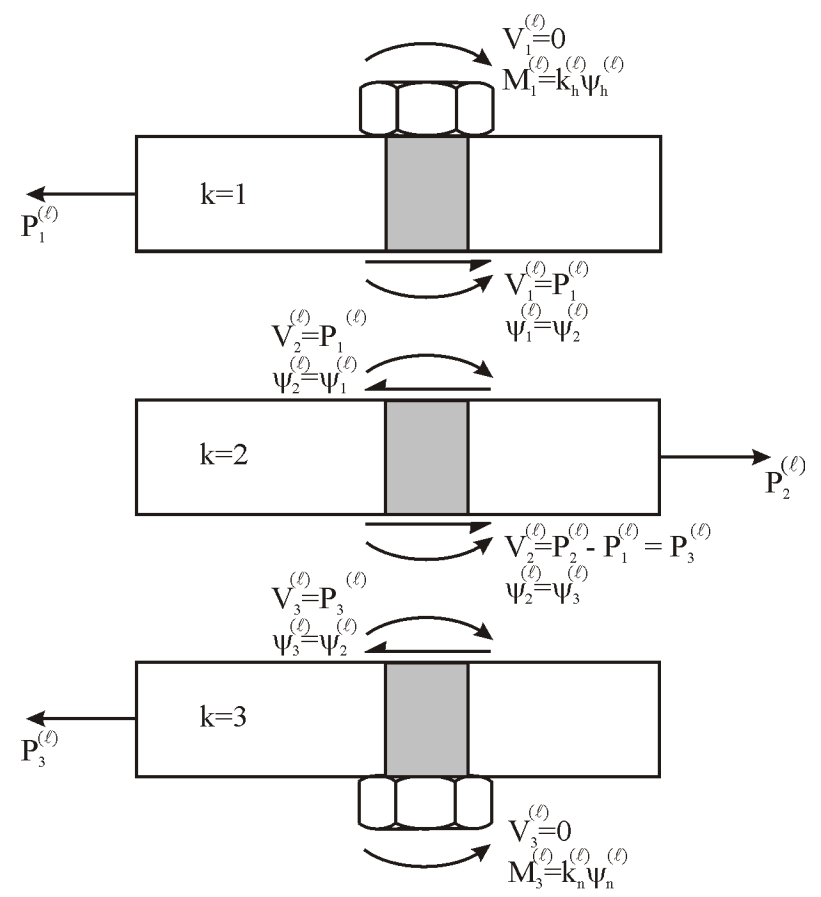

(b)

Fig. 5 Free-body diagrams of laminates for a (a) single- and (b) double-lap joint. 


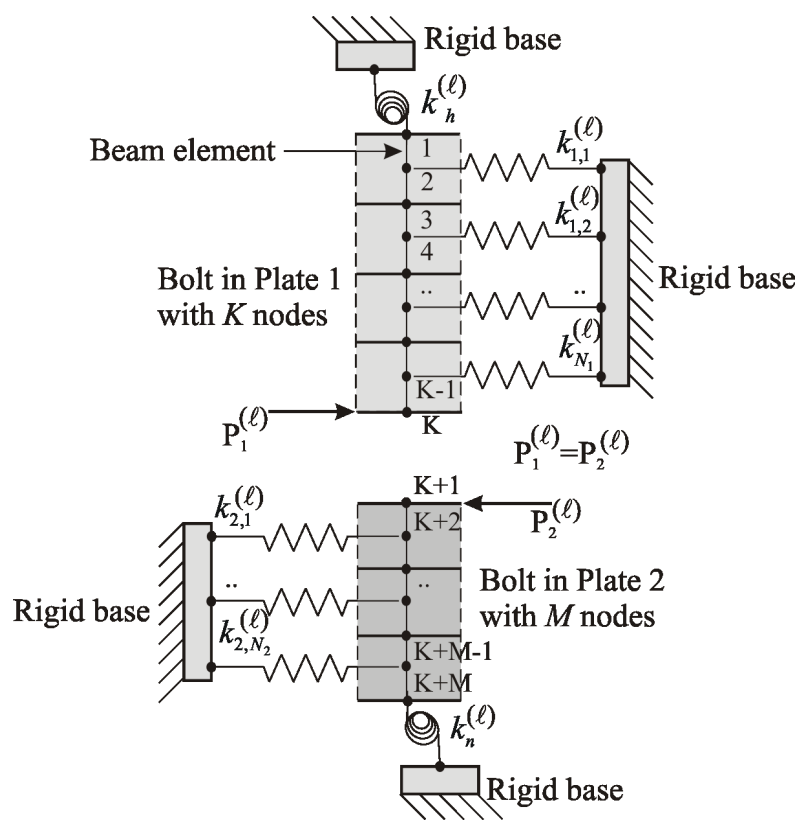

(a)

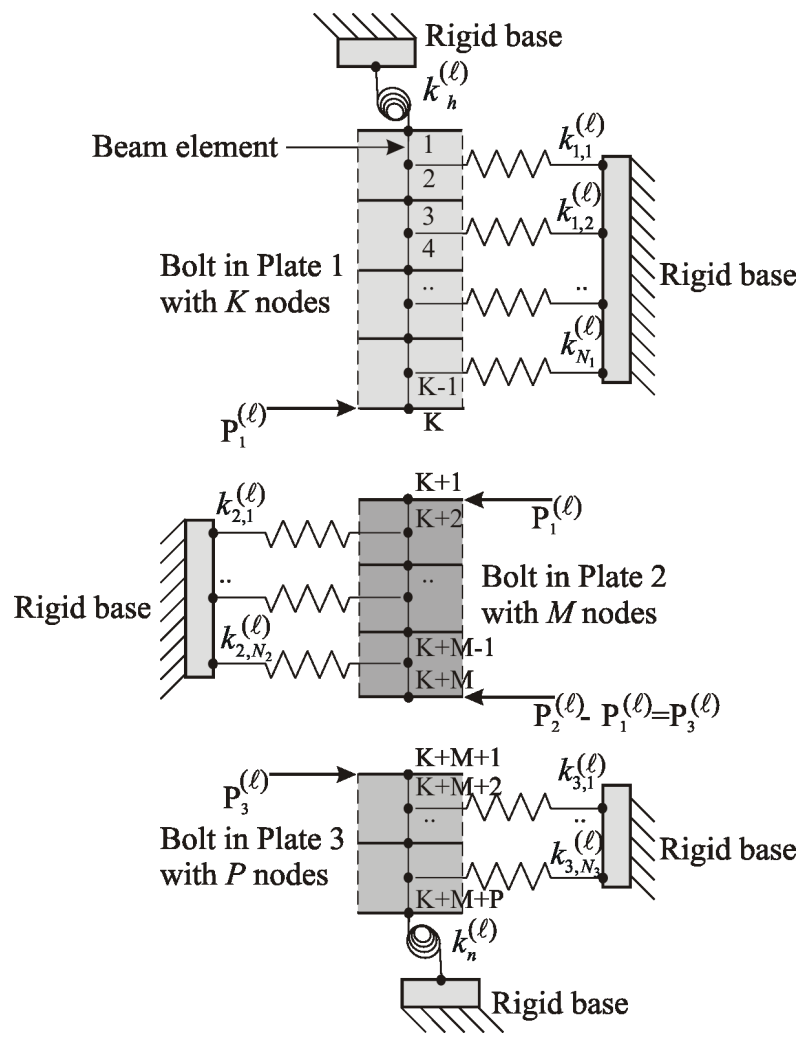

(b)

Fig. 6 The finite element model of a bolt in a (a) single-and (b) double-lap joint.
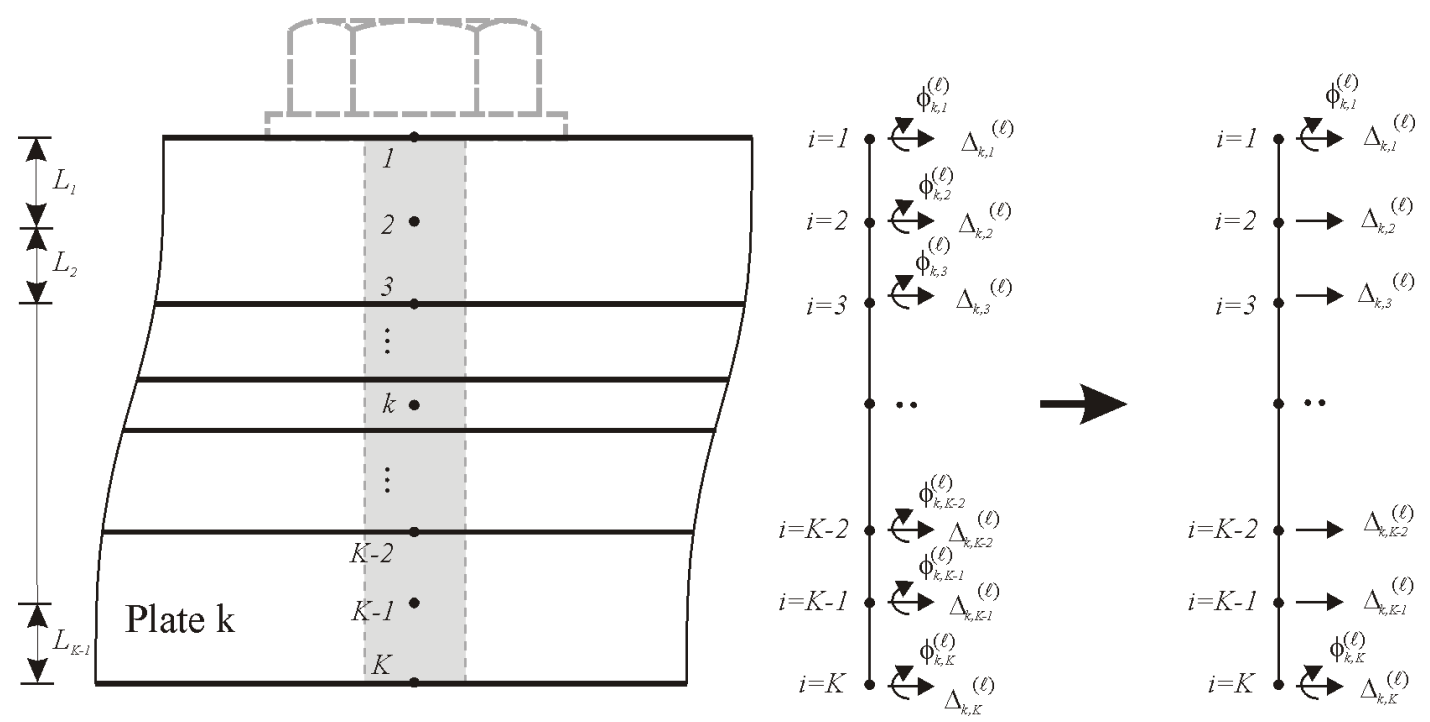

Fig. 7 Bolt discretization in the $\boldsymbol{k}^{\text {th }}$ plate after static condensation. 
Spring Stiffness Coefficients. As suggested by Ramkumar et $\mathrm{al}^{2}$, the translational spring stiffness coefficients, $k_{k, i}^{(\ell)}$, representing the $i^{\text {th }}$ ply of the $k^{\text {th }}$ laminate near the $\ell^{\text {th }}$ bolt are approximated by

$$
k_{k, i}^{(\ell)}=\frac{p_{k, i}^{(\ell)}}{\gamma_{k}^{(\ell)}}, \quad i=1, N_{k}
$$

where $p_{k, i}^{(\ell)}$ is the load exerted by the $\ell^{\text {th }}$ bolt on the $i^{\text {th }}$ ply of the $k^{\text {th }}$ laminate and $\gamma_{k}^{(\ell)}$ represents the maximum hole enlargement of the $\ell^{\text {th }}$ hole in the $k^{\text {th }}$ laminate. The number of plies in the $k^{\text {th }}$ laminate is denoted by $N_{k}$.

As part of the two-dimensional in-plane bolted joint analysis, the load exerted by the bolt on the $i^{\text {th }}$ ply of the $k^{\text {th }}$ laminate near the $\ell^{\text {th }}$ hole, $p_{k, i}^{(\ell)}$, is computed as

$$
p_{k, i}^{(\ell)}=\sqrt{\left(p_{(k, i) x}^{(\ell)}\right)^{2}+\left(p_{(k, i) y}^{(\ell)}\right)^{2}}
$$

where $p_{(k, i) x}^{(\ell)}$ and $p_{(k, i) y}^{(\ell)}$ represent its components in the $x$ - and $y$-directions. These components are computed by integrating the radial stresses in each ply as

$$
p_{(k, i) x}^{(\ell)}=a_{k, \ell} \int_{0}^{2 \pi} \sigma_{r r}^{(k, i)}\left(r=a_{k, \ell}, \theta\right) \cos \theta d \theta
$$

and

$$
p_{(k, i) y}^{(\ell)}=a_{k, \ell} \int_{0}^{2 \pi} \sigma_{r r}^{(k, i)}\left(r=a_{k, \ell}, \theta\right) \sin \theta d \theta
$$

in which $a_{k, \ell}$ is the radius of the $\ell^{\text {th }}$ hole in the $k^{\text {th }}$ laminate, and $\sigma_{r r}^{(k, i)}\left(r=a_{k, \ell}, \theta\right)$ represents the radial stress distribution in the $i^{\text {th }}$ ply of the $k^{\text {th }}$ laminate near the $\ell^{\text {th }}$ hole.

Under plane-stress assumptions, the stress and strain components are related by

$$
\boldsymbol{\sigma}^{(k, i)}=\overline{\boldsymbol{Q}}_{k, i} \boldsymbol{\varepsilon}^{(k)}
$$

in which $\overline{\boldsymbol{Q}}_{k, i}$ represents the reduced stiffness matrix for the $i^{\text {th }}$ ply of the $k^{\text {th }}$ laminate. The Cartesian stress components in the $i^{\text {th }}$ ply of the $k^{\text {th }}$ laminate and the Cartesian strain components, uniform through the thickness of the $k^{\text {th }}$ laminate, are included in the vectors of $\boldsymbol{\sigma}^{(k, i)}$ and $\boldsymbol{\varepsilon}^{(k)}$. This stress state in each ply is employed in the prediction of the initial ply failure load, $F_{k, i}^{(\ell) I N}$, and the corresponding failure mode.

As shown in Fig. 2, the maximum hole enlargement, $\gamma_{k}^{(\ell)}$, is defined as the absolute value of the difference between the radial displacements, $u_{k}^{(\ell)}\left(r=a_{k, \ell}, \theta=\theta_{1}\right)$ and $u_{k}^{(\ell)}\left(r=a_{k, \ell}, \theta=\theta_{2}\right)$,of points 1 and 2 on the hole boundary in the direction of the bolt load

$$
\gamma_{k}^{(\ell)}=\left|u_{k}^{(\ell)}\left(r=a_{k, \ell}, \theta=\theta_{2}\right)-u_{k}^{(\ell)}\left(r=a_{k, \ell}, \theta=\theta_{1}\right)\right|
$$

where the radial displacements are obtained from the in-plane bolted joint analysis. The maximum holeenlargement, $\gamma_{k}^{(\ell)}$, can be different for each laminate of the bolted joint, but is uniform through the thickness. Also, it is specific to each bolt-hole in the laminate because it is dependent on the deformation response and the bolt load distribution. The head and nut rotational stiffness coefficients, $k_{h}^{(\ell)}$ and $k_{n}^{(\ell)}$, respectively, have values close to zero for free-end conditions and to infinity for protruding head bolts under high torque. The stiffness matrix becomes singular if these coefficients approach zero.

The analysis results include displacements and rotations, $\Delta_{k, j}^{(\ell)}$ and $\phi_{k, j}^{(\ell)}$, at the $j^{\text {th }}$ node, as well as the spring forces, $f_{k, i}^{(\ell)}$, at the $i^{\text {th }}$ ply of the $k^{\text {th }}$ laminate near the $\ell^{\text {th }}$ hole. The effect of through-the-thickness variation is invoked in the in-plane stress analysis by considering the spring forces, $f_{k, i}^{(\ell)}$, as the corrected ply loads.

\section{Progressive Failure Prediction}

There are three major failure modes in bolted composite lap joints: net-section, shear-out, and bearing (Fig. 8). The net-section failure is associated with fiber and matrix tension failure and shear-out and bearing failures are associated with fiber and matrix shear and compression failures, respectively. Failure in bolted laminates can be predicted by evaluating either the specific stress components or their interaction at characteristic distances from the hole boundary. Although any one of these criteria is applicable to the prediction of the failure of a laminate or a ply, values of the characteristic distances and the unnotched strength parameters of the material are scarce.

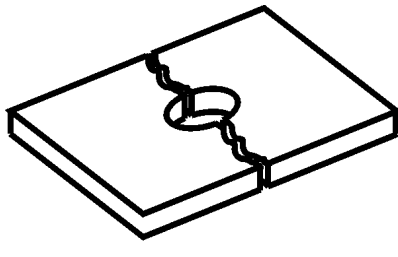

Net-tension Failure

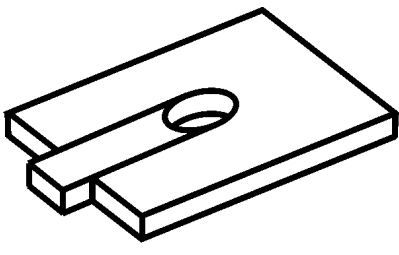

Shear-out Failure

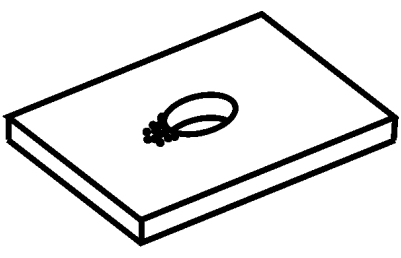

Bearing Failure

Fig. 8 Primary failure modes in bolted composite joints. 
The point and average stress criteria introduced by Whitney and Nuismer ${ }^{3}$ disregarded the interaction among the stress components. However, they are widely used in engineering practice for predicting the failure stress and failure modes because of their well-established values of the characteristic distances. ${ }^{2,5,-6}$ Both of these criteria predict net-section, shear-out, and bearing failures when the stress components at specific locations reach their corresponding unnotched strength levels. The characteristic distances of $a_{o}^{n s}$ for netsection, $a_{o}^{b r}$ for bearing, and $a_{o}^{s o}$ for shear-out failures, as well as the shear-out and net-section planes (denoted by the $n$ and $s$ lines), are shown in Fig. 9. According to the point stress criterion, the net-section failure occurs when the normal stress, $\sigma_{s s}$, at a distance $a_{o}^{n s}$ from the bolt-hole boundary along the net-section plane reaches the unnotched tensile strength of a ply, $X_{t}$. If $\sigma_{s s}$ at a distance $a_{o}^{b r}$ from the bolt hole boundary reaches the unnotched compressive strength of a ply, $X_{c}$, bearing failure occurs. Shear-out failure occurs when the shear stress, $\sigma_{n s}$, at a distance $a_{o}^{s o}$ from the bolt-hole boundary along the shear-out planes reaches the unnotched shear strength of a ply, $X_{s}$. The average stress failure criterion is based on the average values of the corresponding stress components over the characteristic distances of $\left(0, a_{0}^{n s}\right),\left(0, a_{0}^{b r}\right)$, and $\left(0, a_{0}^{s o}\right)$.

Under the specified external loading, the ratios $C_{j, i}^{(k, \ell)}(j=n s, b r, s o)$ of the unnotched strength parameters to the average stresses associated with the netsection $(j=n s)$, bearing $(j=b r)$, and shear-out $(j=s o)$ failure modes at the $i^{\text {th }}$ ply of the $k^{\text {th }}$ laminate near the $\ell^{\text {th }}$ hole are defined in the form

$$
C_{n s, i}^{(k, \ell)}=\frac{X_{t}^{(k, i)}}{\bar{\sigma}_{s s}^{(k, i)}} \text { for net-section failure mode }
$$

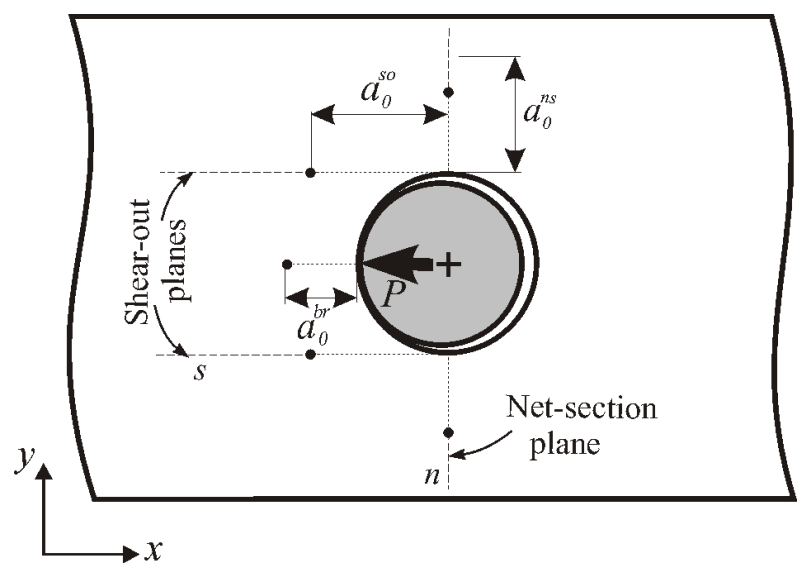

Fig. 9 Characteristic distances for point and average stress failure criteria.

$$
\begin{aligned}
& C_{b r, i}^{(k, \ell)}=\frac{X_{c}^{(k, i)}}{\bar{\sigma}_{s s}^{(k, i)}} \text { for bearing failure mode } \\
& C_{s o, i}^{(k, \ell)}=\frac{X_{s}^{(k, i)}}{\bar{\sigma}_{n s}^{(k, i)}} \text { for shear-out failure mode }
\end{aligned}
$$

in which $\bar{\sigma}_{s s}^{(k, i)}$ and $\bar{\sigma}_{n s}^{(k, i)}$ are averaged normal and shear stresses over the characteristic distances $\left(0, a_{0}^{n s}\right)$, $\left(0, a_{0}^{b r}\right)$, and $\left(0, a_{0}^{s o}\right)$.

The initial ply failure load, $F_{k, i}^{(\ell) I N}$, and its associated failure mode are established by

$$
F_{k, i}^{(\ell) I N}=\min \left(C_{j, i}^{(k, \ell)}\right) p_{k, i}^{(\ell)}, \quad(j=n s, b r, s o)
$$

After the initial failure, a ply is assumed to continue sustaining the applied load according to a bilinear behavior, shown in Fig. 10. The value of the ultimate ply failure load, $F_{k, i}^{(\ell) U L}$, is defined by

$$
F_{k, i}^{(\ell) U L}=H F_{k, i}^{(\ell) I N}
$$

where the factor $H$ varies as $1.02,1.50$, and 1.12 for net-section, bearing, and shear-out failure modes, respectively, as suggested by Ramkumar et al. ${ }^{2}$

Due to the bilinear ply load behavior, the applied joint load is increased incrementally while predicting ply failure subsequent to the initial ply failure. At each load increment, the corrected ply loads, $f_{k, i}^{(\ell)}$, are compared to the initial and ultimate ply failure loads of $F_{k, i}^{(\ell) I N}$ and $F_{k, i}^{(\ell) U L}$, which are predicted according to the average stress criterion of two-dimensional analysis.

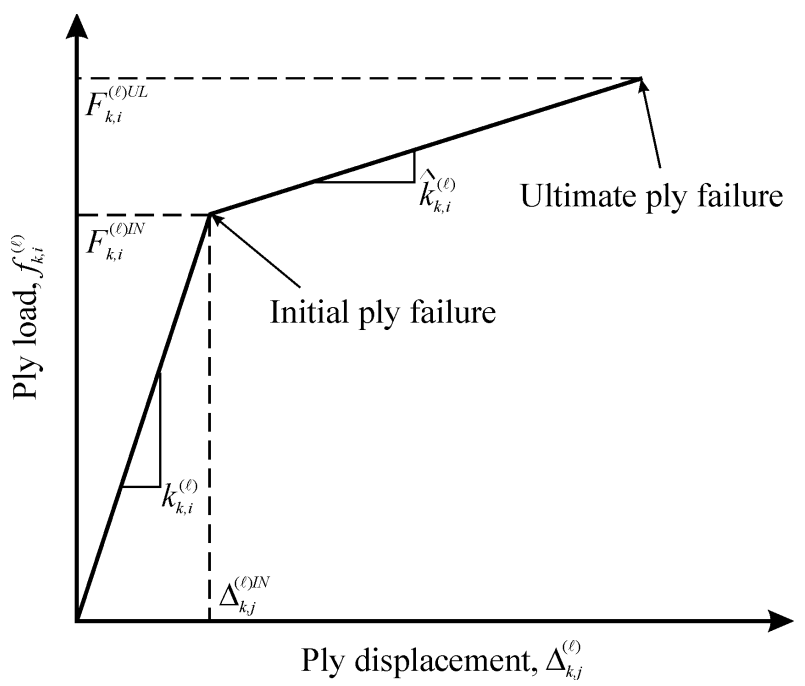

Fig. 10 Bilinear ply behavior. 
For an undamaged ply, if the corrected ply load of $f_{k, i}^{(\ell)}$ exceeds the corresponding initial ply failure load of $F_{k, i}^{(\ell) I N}$, the ply experiences initial failure. Accordingly, as suggested by Ramkumar et al., ${ }^{2}$ the initial ply stiffness of $k_{k, i}^{(\ell)}$ is reduced to $\hat{k}_{k, i}^{(\ell)}$. The reduced ply stiffness, $\hat{k}_{k, i}^{(\ell)}$, is defined by

$$
\hat{k}_{k, i}^{(\ell)}=\alpha k_{k, i}^{(\ell)}
$$

in which the parameter $\alpha$ is assumed to be 0.1 . For a damaged ply, if the corrected ply load of $f_{k, i}^{(\ell)}$ exceeds the corresponding ultimate failure load of $F_{k, i}^{(\ell) U L}$, the ply experiences total failure. Consequently, the ply stiffness is reduced to zero.

Based on the bilinear behavior of the ply load shown in Fig. 10, the ply load at the $i^{\text {th }}$ ply of the $k^{\text {th }}$ laminate near the $\ell^{\text {th }}$ bolt can be expressed in terms of the ply displacement as

$$
f_{k, i}^{(\ell)}=k_{k, i}^{(\ell)} \Delta_{k, j}^{(\ell)}
$$

for an undamaged ply, as

$$
f_{k, i}^{(\ell)}=\left(k_{k, i}^{(\ell)}-\hat{k}_{k, i}^{(\ell)}\right) \Delta_{k, j}^{(\ell) I N}+\hat{k}_{k, i}^{(\ell)} \Delta_{k, j}^{(\ell)}
$$

for a damaged ply, and as

$$
f_{k, i}^{(\ell)}=0
$$

for a totally damaged ply, where $j$ denotes the node associated with the translational spring element representing the $i^{\text {th }}$ ply.

When a ply fails, the adjacent plies share the load released by the failed ply. Thus, the failure propagates from ply to ply until the total failure of the laminate. The ultimate joint failure load is defined as the joint load that results in the ultimate failure of half of the plies at a particular bolt location. The minimum of the failure loads predicted for each bolt establishes the strength of the joint. This type of progressive failure analysis can be employed in conjunction with any one of the available failure criteria.

\section{Numerical Results}

The capability of this combined in-plane and through-the-thickness bolted joint analysis is demonstrated by considering single- and double-lap bolted joints joining metal to composite laminates with one, three, and four bolts as shown in Figs. 11-13.

The material properties, stacking sequence and thickness of the plates are the same as those considered by

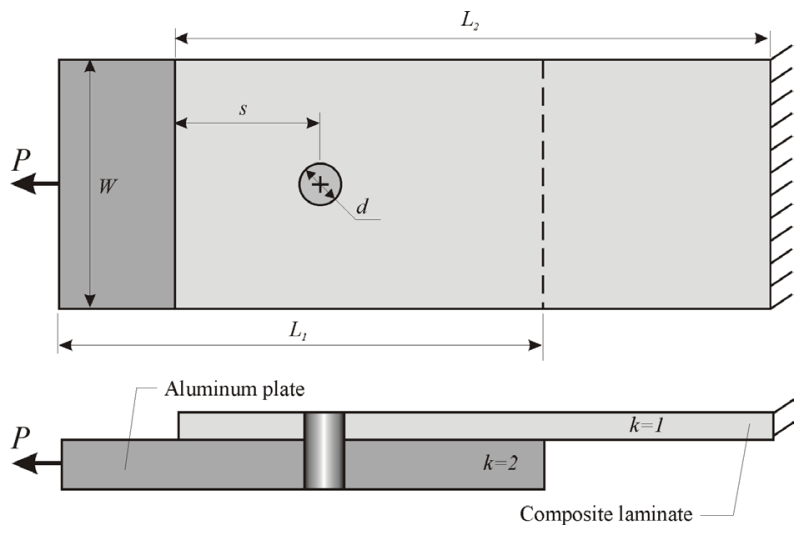

Fig. 11 One-bolt single-lap joint geometry and loading.
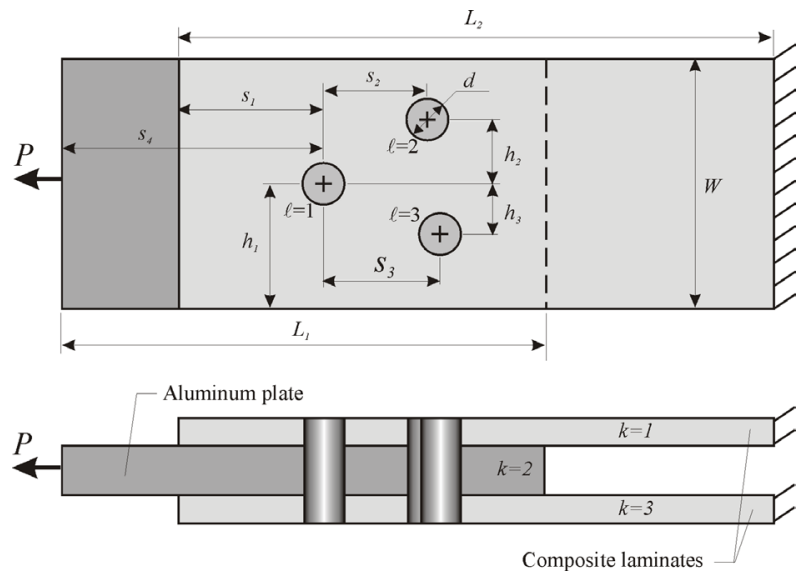

Fig. 12 Three-bolt double-lap joint geometry and loading.

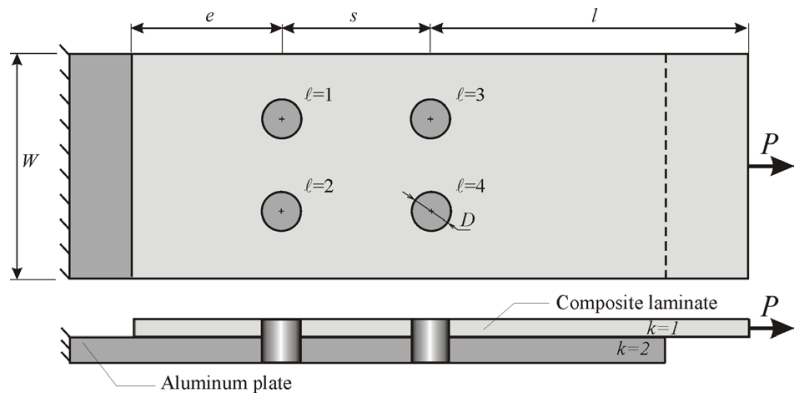

Fig. 13 Four-bolt single-lap joint geometry and loading. 
Ramkumar et al. ${ }^{2}$ The metal plates are made of aluminum with Young's modulus $E_{a}=10.1 \mathrm{Msi}$ and Poisson's ratio $v_{a}=0.3$. The bolts are of steel with a Young's modulus $E_{s}=30.0 \mathrm{Msi}$ and Poisson's ratio $v_{s}=0.3$. Although not a limitation of the analysis method, in these configurations, the bolt and hole diameters are equal, leading to zero clearance. The aluminum plates have a thickness of 0.31 in. The thickness of the laminate is 0.12 in with stacking sequence of $\left[\left(45^{\circ} / 0^{\circ} /-45^{\circ} / 0^{\circ}\right)_{2} 0^{\circ} / 90^{\circ}\right]_{s}$. The material properties for each ply are specified as $E_{L}=18.5 \mathrm{Msi}$, $E_{T}=1.9 \mathrm{Msi}, G_{L T}=0.85 \mathrm{Msi}$, and $v_{L T}=0.3$. The high value of torque applied on the protruding bolt-head is specified by the head and nut rotational stiffness coefficients of $k_{h}=10^{12} \mathrm{lbs}-$ in and $k_{n}=10^{12} \mathrm{lbs}-\mathrm{in}$. The failure prediction is performed by employing the average stress criterion along with a bilinear stiffness reduction after the initial failure of each ply. The characteristic length parameters for the average stress failure criterion are taken as $a_{0}^{n s}=0.1$ in, $a_{0}^{s o}=0.08$ in, and $a_{0}^{b r}=0.025 \mathrm{in}$. The unnotched strength parameters of the ply for each orientation in the stacking sequence are given in Table 1.

Table 1 Unnotched strength values in $X$-direction.

\begin{tabular}{|c|c|c|c|}
\hline $\begin{array}{c}\text { Ply } \\
\text { orientation } \\
\text { (degree) }\end{array}$ & $\begin{array}{c}X_{t}, \text { Net- } \\
\text { section } \\
\text { tensile (ksi) }\end{array}$ & $\begin{array}{c}X_{c}, \\
\text { Bearing } \\
(\mathrm{ksi})\end{array}$ & $\begin{array}{c}X_{s}, \\
\text { Shear- } \\
\text { out } \\
(\mathrm{ksi})\end{array}$ \\
\hline 0 & 230.0 & 320.0 & 17.3 \\
\hline 45 & 40.0 & 56.0 & 95.0 \\
\hline-45 & 40.0 & 56.0 & 95.0 \\
\hline 90 & 9.5 & 38.9 & 17.3 \\
\hline
\end{tabular}

As part of the finite element modeling, the section of the bolt in contact with the composite laminate is discretized with 41 nodes in order to represent 20 plies of the laminate lay-up. Because the aluminum plate is thicker than the laminate, it is discretized with 81 nodes leading to 40 layers of aluminum.

\section{One-Bolt Single-Lap Metal to Composite Joint}

The geometrical parameters shown in Fig. 11 are defined by $W=1.875 \mathrm{in}, d=0.3125$ in, $L_{1}=3.6$ in, $L_{2}=4.4375 \mathrm{in}$, and $s=0.9375$ in. The initial applied load of $P=1875 \mathrm{lbs}$ is uniformly distributed along one edge of the aluminum plate while the other end of the laminate is constrained. The variations of radial and tangential stresses around the hole boundary in aluminum and composite plates are shown in Figs. 14 and 15, respectively. These figures demonstrate the capability of the two-dimensional analysis to capture the stress concentrations and provide the contact region around

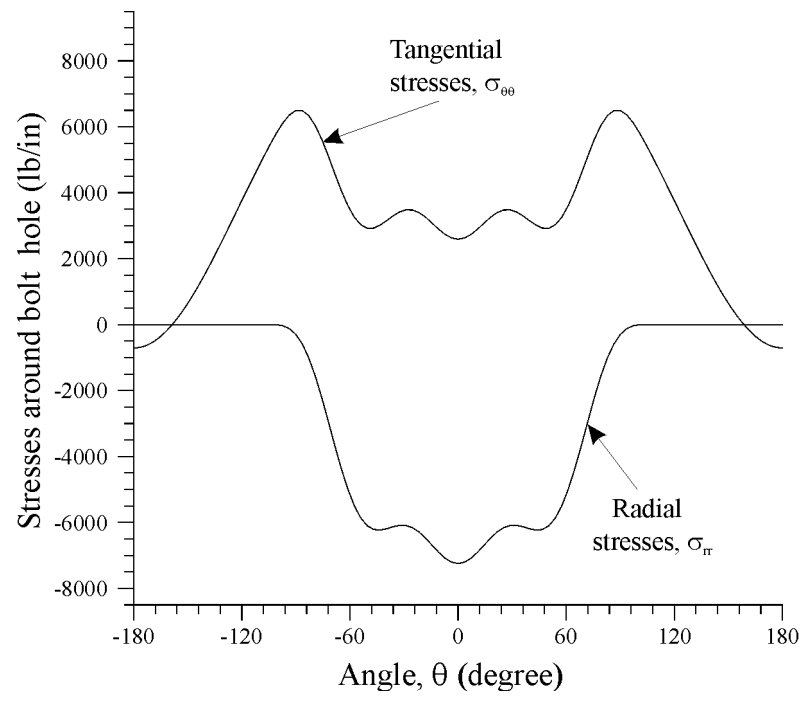

Fig. 14 Stress variation around the hole boundary in an aluminum plate.

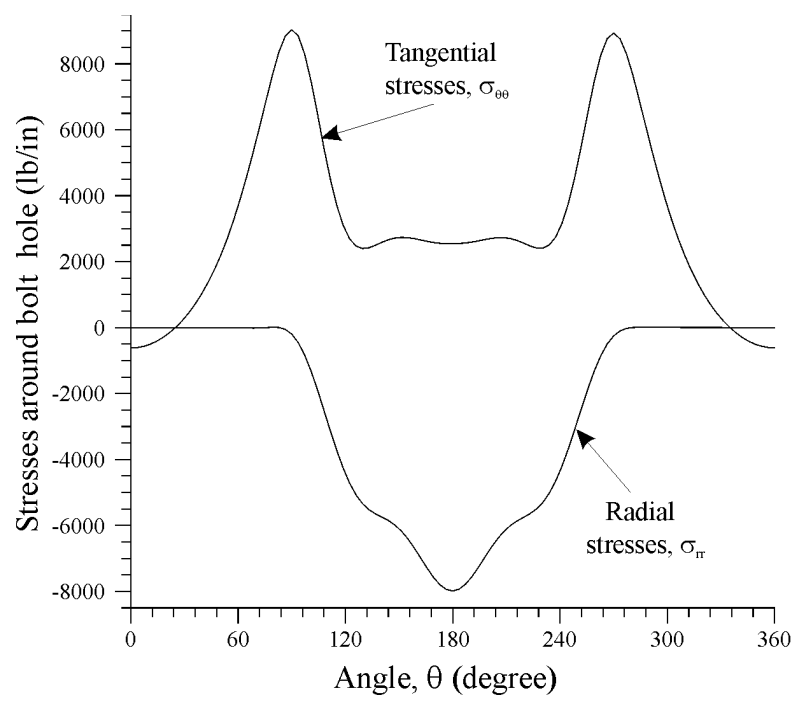

Fig. 15 Stress variation around the hole boundary in a composite laminate.

the bolt hole. The segment of the radial stresses with negative values establishes the contact region between the bolt and hole boundary. As expected, there are zero shear stresses on the hole boundary because of the absence of friction.

Based on the in-plane stress analysis, the maximum hole enlargements are computed as $\gamma_{1}^{(1)}=6.808 \times 10^{-4}$ in and $\gamma_{2}^{(1)}=2.891 \times 10^{-4}$ in for the aluminum and laminate, respectively. Invoking these values in Eq. (1), the stiffness of the spring representing the aluminum layer has a value of $k_{1, i}^{(1)}=69,597 \mathrm{lb} /$ in with $i=1,40$. The spring stiffness value for each ply of the laminate is 
calculated as $k_{2, m}^{(1)}=34,286 \mathrm{lb} / \mathrm{in}, \quad k_{2, n}^{(1)}=52,586 \mathrm{lb} / \mathrm{in}$, $k_{2, p}^{(1)}=34,654 \mathrm{lb} / \mathrm{in}$, and $k_{2, q}^{(1)}=8,446 \mathrm{lb} / \mathrm{in}$, where the subscripts $m, n, p$, and $q$ represent $45^{\circ}, 0^{\circ},-45^{\circ}$, and $90^{\circ}$ plies, respectively.

The variation of the nodal displacements, $\Delta_{1, j}^{(1)}$ with $(j=1,81)$ and $\Delta_{2, j}^{(1)}$ with $(j=1,41)$, illustrates the bolt/hole deformations in Fig. 16. As observed in this figure, the deformations in the composite laminate are larger than those in the metal plate as dictated by the material properties and laminate thickness. As expected, the specified large values for head and nut rotational stiffness coefficients, $k_{h}$ and $k_{n}$, result in zero slopes at the ends of the bolt. The maximum bolt/hole deformations occur at the interface of the two plates, indicating the location of the major load transfer, as reflected in Fig. 17, which depicts the variation of the load distribution through the thickness of the joint. As expected, the load distribution through the thickness of aluminum plate varies continuously. However, the ply loads corresponding to the composite laminate change abruptly, depending on the fiber orientation. This behavior is dictated by the material property discontinuity in the thickness direction resulting in a different stress state in each ply.

As presented in Table 2, the initial ply failure is predicted at a load level of $P=3,656 \mathrm{lbs}$, with a netsection failure mode in ply number 10 with a $90^{\circ}$ fiber orientation. As the applied joint load is increased incrementally, the plies with a $90^{\circ}$ fiber orientation continue failing in the net-section failure mode. Their failure is followed by a mixture of $\pm 45^{\circ}$ and $0^{\circ}$ plies in the netsection and bearing failure modes, respectively. The load increments resulting in no failure have been omitted in Table 2.

At load increment 56, ply number 1 with a $45^{\circ}$ fiber orientation ultimately fails at a load level of $P=$ $5,336 \mathrm{lbs}$. This ply failure is followed by eleven different ply failures at the same load level. Therefore, the ultimate joint failure is reached at load increment 67 at a load level of 5,336 lbs. This prediction is in acceptable agreement with the experimental measurement of 4,910 lbs reported by Ramkumar et al. ${ }^{2}$

\section{Three-Bolt Double-Lap Metal to Composite Joint}

The geometrical parameters shown in Fig. 12 are defined by $W=2.05 \mathrm{in}, L_{1}=3.6 \mathrm{in}, L_{2}=4.525 \mathrm{in}, s_{1}$ $=1.025 \mathrm{in}, s_{2}=1.0 \mathrm{in}, s_{3}=0.9 \mathrm{in}, s_{4}=1.8 \mathrm{in}, h_{1}=$ $1.025 \mathrm{in}, h_{2}=0.5 \mathrm{in}, h_{3}=0.4 \mathrm{in}$, and $d=0.3125 \mathrm{in}$. The initial joint load of $P=205 \mathrm{lbs}$ is applied to the aluminum plate while the ends of the composite laminates are constrained. The maximum hole enlargement values associated with each bolt hole are computed from the two-dimensional analysis and are pre- sented in Table 3, and the spring stiffness values for each ply are in Table 4.

The through-the-thickness variation of the ply loads near bolt number 3 is shown in Fig. 18. The corresponding bolt/hole deformations are depicted in Fig. 19. As observed in these figures, the most pronounced deformation occurs in plies located along the plate interfaces. Both deformations and ply load distributions are identical for composite laminates due to the presence of symmetry in the material and geometry.

Bolts 2 and 3 exert higher loads on the composite than bolt 1 . The sequence ply failure loads and modes associated with each bolt are different because of the different strain states in the laminate near each bolt hole.

As presented in Table 5, the initial ply failure near bolt 1 occurs at a load level of 22,402 lbs, in ply number 19 with a $45^{\circ}$ fiber orientation, in the shear-out failure mode. Part of the laminate near bolt 1 becomes unstable at load increment 23 , corresponding to a load of $24,745 \mathrm{lbs}$, in ply 10 with a $90^{\circ}$ fiber orientation, in the net-section ultimate failure. At this load level, seventeen more failures occur in the composite laminate before the laminate is assumed to ultimately fail at load increment 39.

As presented in Tables 6 and 7, the initial ply failures near bolts 2 and 3 occur at 13,124 lbs and 12,769 lbs, respectively, in ply 11 with a $90^{\circ}$ fiber orientation, in the net-section failure mode. The progress of failure near bolt 2 is presented in Table 6 . Starting at load increment 46 and until 64, failure occurs for nineteen increments in different plies at a load of 18,225 lbs, and the joint can still carry more load. Finally, ultimate failure of the joint occurs at load increment 69, corresponding to a load level of $19,155 \mathrm{lbs}$, in ply 2 with a $0^{\circ}$ fiber orientation, in shear-out ultimate failure.

A similar failure behavior is observed near bolt 3 , as presented in Table 7. At load increment 24, corresponding to a load of $13,965 \mathrm{lbs}$, failure occurs in ply 1 with a $45^{\circ}$ fiber orientation, in the net-section failure mode, followed by fifteen failures in different plies at the same load level until ultimate joint failure.

Thus, the ultimate joint failure load is computed as 13,965 lbs near bolt 3 . As shown in Table 7, the sequence of ply failure indicates that $90^{\circ}$ and $\pm 45^{\circ}$ plies fail with the net-section failure mode while $0^{\circ}$ plies fail with the shear-out failure mode.

\section{Four-Bolt Single-Lap Metal to Composite Joint}

The geometrical parameters for the four-bolt doublelap joint shown in Fig. 13 are defined by $W=3.125$ in, $s=1.25$ in, $e=0.9375$ in, $\ell=2.75$ in, and $D=0.3125$ in. 


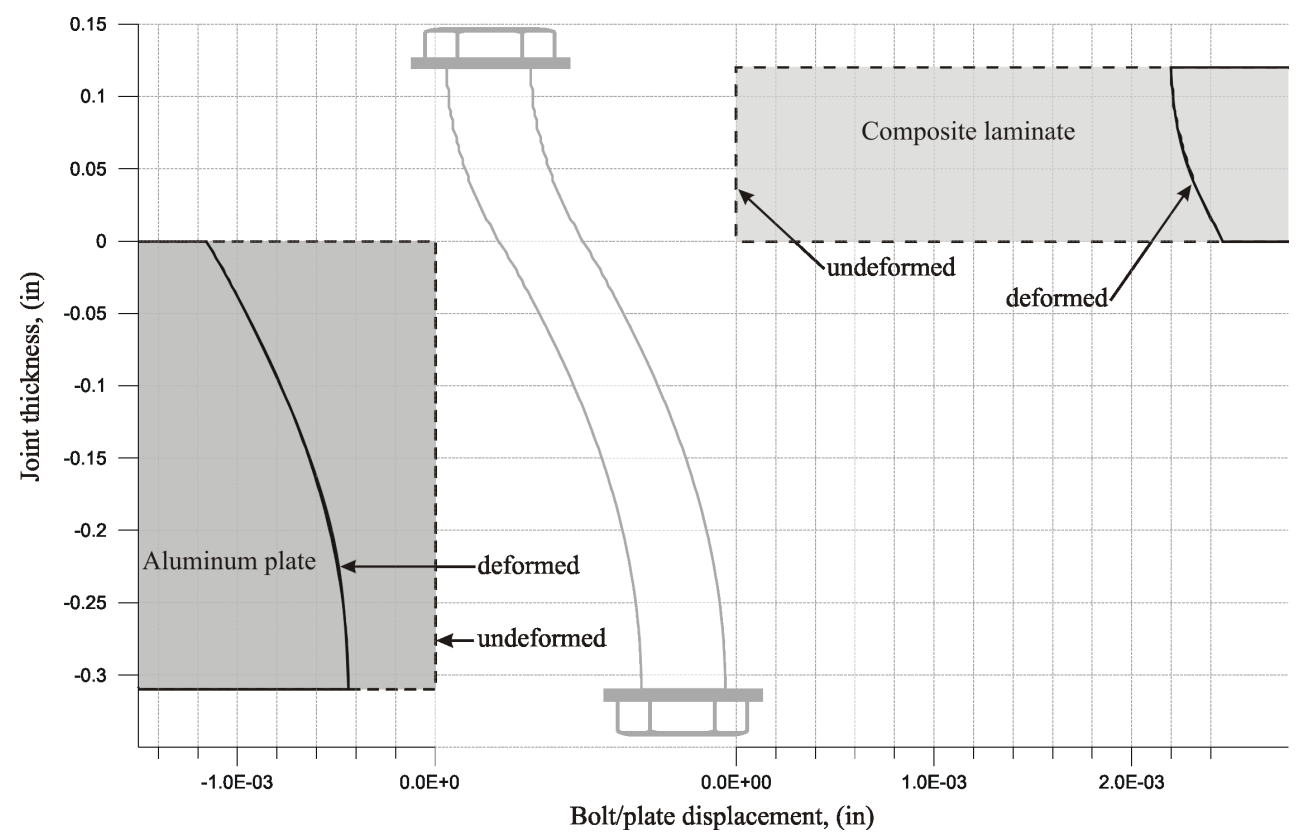

Fig. 16 Variation of bolt/plate displacement through the joint thickness.

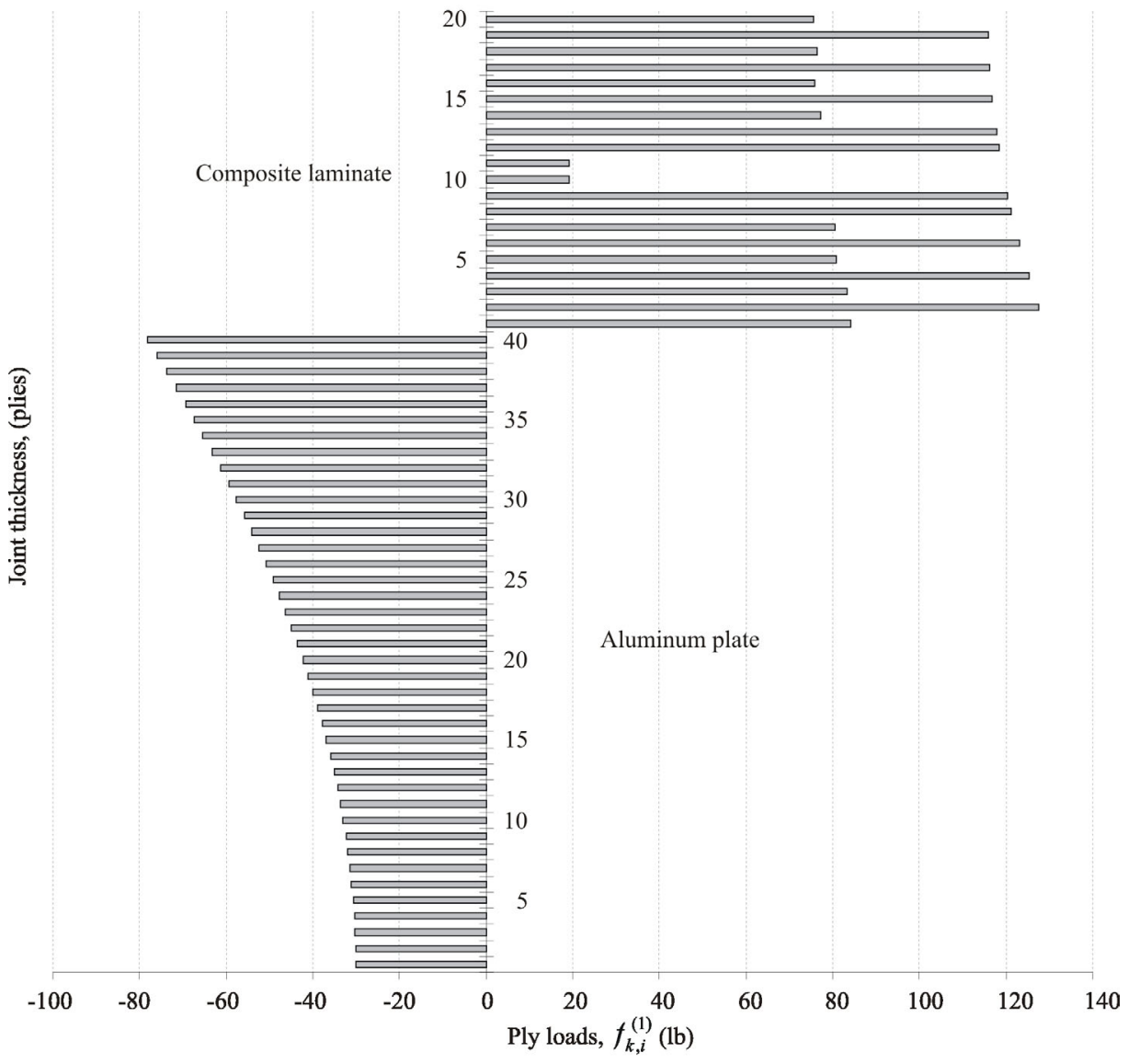

Fig. 17 Variation of ply loads through the joint thickness. 
Table 2 Progressive ply failure in one-bolt single-lap joint.

\begin{tabular}{|c|c|c|c|c|}
\hline $\begin{array}{c}\text { Load } \\
\text { increment }\end{array}$ & $\begin{array}{l}\text { Applied joint } \\
\text { load, (lb) }\end{array}$ & $\begin{array}{c}\text { Ply } \\
\text { number }\end{array}$ & $\begin{array}{c}\text { Ply } \\
\text { orientation, } \\
\text { (degree) }\end{array}$ & Failure mode \\
\hline 1 & 3656 & 10 & 90 & net-section \\
\hline 3 & 3693 & 11 & 90 & net-section \\
\hline 19 & 4287 & 11 & 90 & net-section ultimate \\
\hline 22 & 4373 & 10 & 90 & net-section ultimate \\
\hline 34 & 4879 & 1 & 45 & net-section \\
\hline 37 & 4977 & 3 & -45 & net-section \\
\hline 39 & 5027 & 5 & 45 & net-section \\
\hline 41 & 5077 & 2 & 0 & bearing \\
\hline 43 & 5128 & 4 & 0 & bearing \\
\hline 44 & 5128 & 7 & -45 & net-section \\
\hline 46 & 5179 & 6 & 0 & bearing \\
\hline 48 & 5231 & 8 & 0 & bearing \\
\hline 50 & 5283 & 9 & 0 & bearing \\
\hline 51 & 5283 & 14 & -45 & net-section \\
\hline 52 & 5283 & 16 & 45 & net-section \\
\hline 53 & 5283 & 18 & -45 & net-section \\
\hline 54 & 5283 & 20 & 45 & net-section \\
\hline 56 & 5336 & 1 & 45 & net-section ultimate \\
\hline 57 & 5336 & 3 & -45 & net-section ultimate \\
\hline 58 & 5336 & 5 & 45 & net-section ultimate \\
\hline 59 & 5336 & 7 & -45 & net-section ultimate \\
\hline 60 & 5336 & 12 & 0 & bearing \\
\hline 61 & 5336 & 13 & 0 & bearing \\
\hline 62 & 5336 & 14 & -45 & net-section ultimate \\
\hline 63 & 5336 & 15 & 0 & bearing \\
\hline 64 & 5336 & 15 & 0 & bearing ultimate \\
\hline 65 & 5336 & 12 & 0 & bearing ultimate \\
\hline 66 & 5336 & 13 & 0 & bearing ultimate \\
\hline 67 & 5336 & 16 & 45 & net-section ultimate \\
\hline
\end{tabular}

Table 3 Maximum hole enlargement in a three-bolt double-lap joint.

\begin{tabular}{|c|c|c|c|}
\hline & Bolt 1, (in) & Bolt 2, (in) & Bolt 3 (in) \\
\hline $\begin{array}{c}\text { Aluminum } \\
\text { plate }\end{array}$ & $4.068 \times 10^{-5}$ & $3.053 \times 10^{-5}$ & $3.174 \times 10^{-5}$ \\
\hline $\begin{array}{c}\text { Composite } \\
\text { plate }\end{array}$ & $3.933 \times 10^{-5}$ & $5.723 \times 10^{-5}$ & $6.090 \times 10^{-5}$ \\
\hline
\end{tabular}

Table 4 Spring stiffness values in a three-bolt double-lap joint.

\begin{tabular}{|c|c|c|c|c|}
\hline \multicolumn{2}{|c|}{} & $\begin{array}{c}\text { Bolt 1 } \\
(\mathrm{lb} / \text { in })\end{array}$ & $\begin{array}{c}\text { Bolt 2 } \\
(\mathrm{lb} / \text { in })\end{array}$ & $\begin{array}{c}\text { Bolt 3 } \\
(\mathrm{lb} / \text { in })\end{array}$ \\
\hline \multicolumn{2}{|c|}{ Aluminum plate } & 40,338 & 53,518 & 57,991 \\
\hline \multirow{4}{*}{ Plies in composite plate } & $45^{0}$ & 29,071 & 22,589 & 28,862 \\
\cline { 2 - 5 } & $0^{0}$ & 54,629 & 37,740 & 39,221 \\
\cline { 2 - 5 } & $-45^{0}$ & 38,564 & 24,102 & 21,403 \\
\cline { 2 - 5 } & $90^{0}$ & 9,043 & 5,832 & 6,433 \\
\hline
\end{tabular}




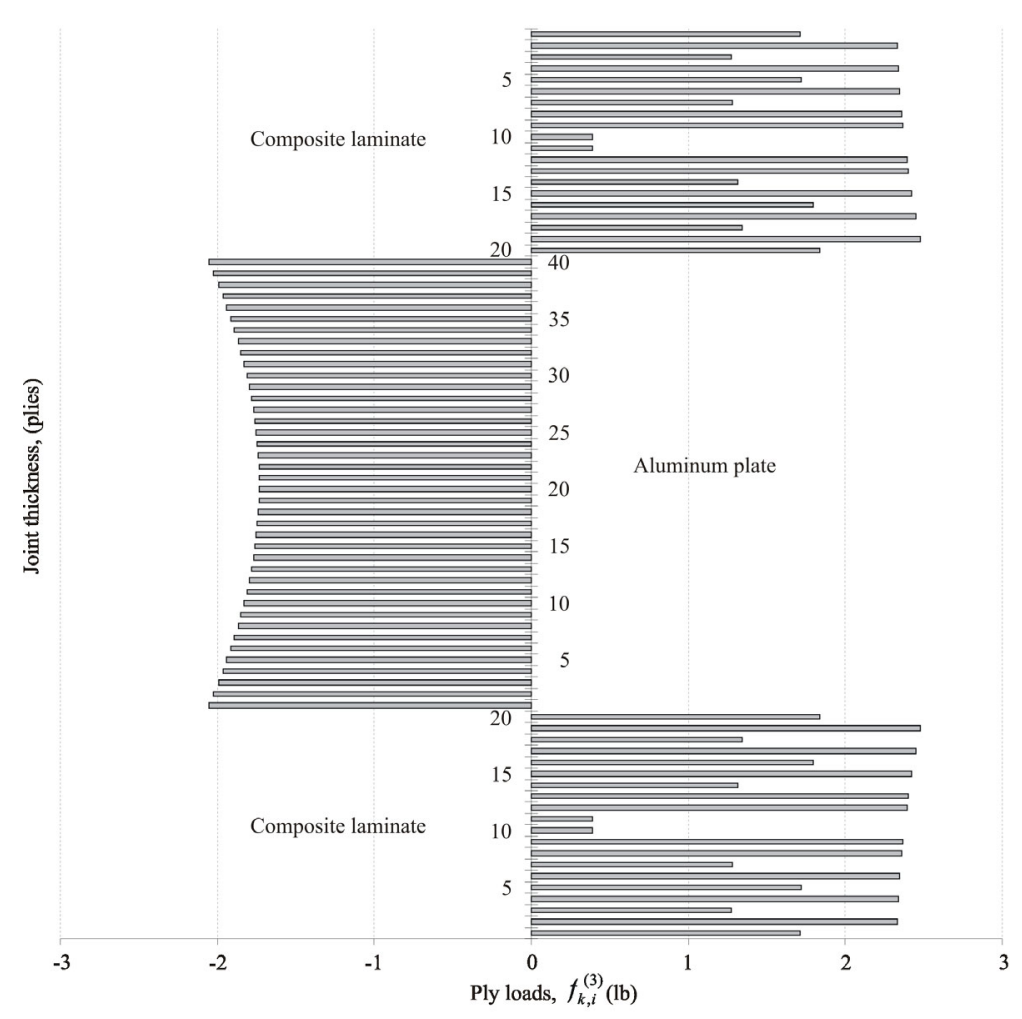

Fig. 18 Variation of ply loads through the joint thickness near bolt 3 in a three-bolt joint.

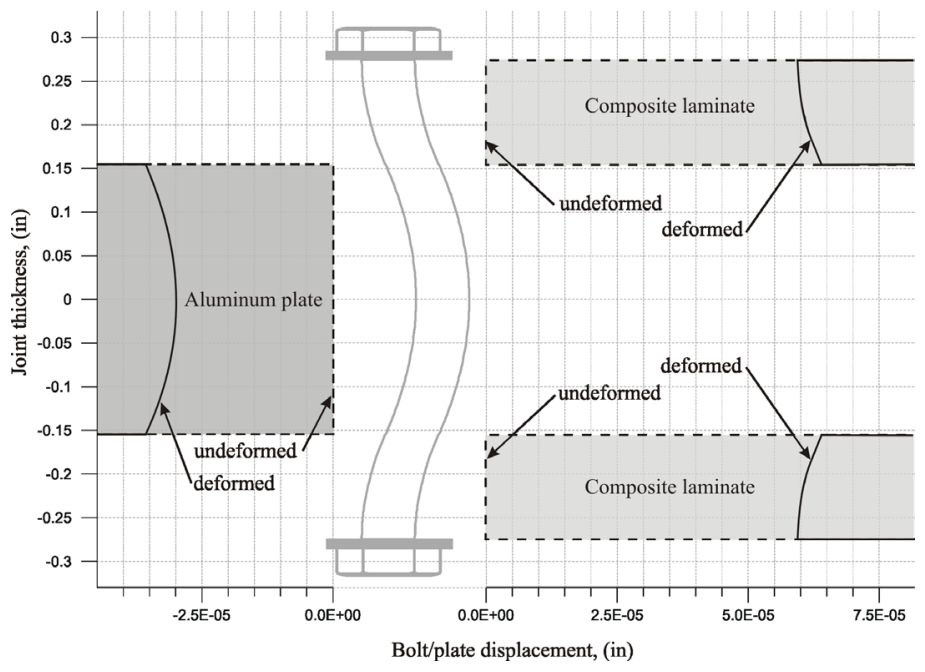

Fig. 19 Variation of bolt/plate displacement through the joint thickness near bolt 3 in a three-bolt joint. 
Table 5 Progressive ply failure for bolt 1 in the three-bolt double-lap joint.

\begin{tabular}{|c|c|c|c|c|c|}
\hline $\begin{array}{c}\text { Load } \\
\text { increment }\end{array}$ & $\begin{array}{l}\text { Bolt load, } \\
\quad \text { (lb) }\end{array}$ & $\begin{array}{l}\text { Applied joint } \\
\text { load, (lb) }\end{array}$ & $\begin{array}{c}\text { Ply } \\
\text { number }\end{array}$ & $\begin{array}{c}\text { Ply } \\
\text { orientation, } \\
\text { (degree) }\end{array}$ & Failure mode \\
\hline 1 & 3601 & 22402 & 19 & 0 & shear-out \\
\hline 4 & 3673 & 22852 & 11 & 90 & net-section \\
\hline 5 & 3673 & 22852 & 17 & 0 & shear-out \\
\hline 7 & 3710 & 23080 & 10 & 90 & net-section \\
\hline 8 & 3710 & 23080 & 15 & 0 & shear-out \\
\hline 10 & 3747 & 23311 & 13 & 0 & shear-out \\
\hline 12 & 3784 & 23544 & 12 & 0 & shear-out \\
\hline 14 & 3822 & 23780 & 8 & 0 & shear-out \\
\hline 15 & 3822 & 23780 & 9 & 0 & shear-out \\
\hline 17 & 3860 & 24017 & 2 & 0 & shear-out \\
\hline 18 & 3860 & 24017 & 4 & 0 & shear-out \\
\hline 19 & 3860 & 24017 & 6 & 0 & shear-out \\
\hline 23 & 3977 & 24745 & 10 & 90 & net-section ultimate \\
\hline 24 & 3977 & 24745 & 14 & -45 & net-section \\
\hline 25 & 3977 & 24745 & 18 & -45 & net-section \\
\hline 26 & 3977 & 24745 & 18 & -45 & net-section ultimate \\
\hline 27 & 3977 & 24745 & 3 & -45 & net-section \\
\hline 28 & 3977 & 24745 & 3 & -45 & net-section ultimate \\
\hline 29 & 3977 & 24745 & 7 & -45 & net-section \\
\hline 30 & 3977 & 24745 & 7 & -45 & net-section ultimate \\
\hline 31 & 3977 & 24745 & 1 & 45 & net-section \\
\hline 32 & 3977 & 24745 & 1 & 45 & net-section ultimate \\
\hline 33 & 3977 & 24745 & 2 & 0 & shear-out ultimate \\
\hline 34 & 3977 & 24745 & 4 & 0 & shear-out ultimate \\
\hline 35 & 3977 & 24745 & 5 & 45 & net-section \\
\hline 36 & 3977 & 24745 & 5 & 45 & net-section ultimate \\
\hline 37 & 3977 & 24745 & 6 & 0 & shear-out ultimate \\
\hline 38 & 3977 & 24745 & 8 & 0 & shear-out ultimate \\
\hline 39 & 3977 & 24745 & 9 & 0 & shear-out ultimate \\
\hline
\end{tabular}


Table 6 Progressive ply failure for bolt 2 in the three-bolt double-lap joint.

\begin{tabular}{|c|c|c|c|c|c|}
\hline $\begin{array}{c}\text { Load } \\
\text { increment }\end{array}$ & $\begin{array}{l}\text { Bolt load, } \\
\text { (lb) }\end{array}$ & $\begin{array}{l}\text { Applied joint } \\
\text { load, (lb) }\end{array}$ & $\begin{array}{c}\text { Ply } \\
\text { number }\end{array}$ & $\begin{array}{c}\text { Ply } \\
\text { orientation, } \\
\text { (degree) }\end{array}$ & Failure mode \\
\hline 1 & 2101 & 13124 & 11 & 90 & net-section \\
\hline 3 & 2122 & 13255 & 10 & 90 & net-section \\
\hline 17 & 2415 & 15086 & 10 & 90 & net-section ultimate \\
\hline 22 & 2513 & 15698 & 11 & 90 & net-section ultimate \\
\hline 26 & 2589 & 16174 & 18 & -45 & net-section \\
\hline 29 & 2641 & 16499 & 14 & -45 & net-section \\
\hline 31 & 2668 & 16664 & 20 & 45 & net-section \\
\hline 33 & 2694 & 16831 & 7 & -45 & net-section \\
\hline 35 & 2721 & 16999 & 3 & -45 & net-section \\
\hline 36 & 2721 & 16999 & 16 & 45 & net-section \\
\hline 40 & 2804 & 17514 & 1 & 45 & net-section \\
\hline 41 & 2804 & 17514 & 5 & 45 & net-section \\
\hline 46 & 2917 & 18225 & 18 & -45 & net-section ultimate \\
\hline 47 & 2917 & 18225 & 3 & -45 & net-section ultimate \\
\hline 48 & 2917 & 18225 & 5 & 45 & net-section ultimate \\
\hline 49 & 2917 & 18225 & 1 & 45 & net-section ultimate \\
\hline 50 & 2917 & 18225 & 7 & -45 & net-section ultimate \\
\hline 51 & 2917 & 18225 & 14 & -45 & net-section ultimate \\
\hline 52 & 2917 & 18225 & 16 & 45 & net-section ultimate \\
\hline 53 & 2917 & 18225 & 12 & 0 & shear-out \\
\hline 54 & 2917 & 18225 & 13 & 0 & shear-out \\
\hline 55 & 2917 & 18225 & 15 & 0 & shear-out \\
\hline 56 & 2917 & 18225 & 17 & 0 & shear-out \\
\hline 57 & 2917 & 18225 & 19 & 0 & shear-out \\
\hline 58 & 2917 & 18225 & 20 & 45 & net-section ultimate \\
\hline 59 & 2917 & 18225 & 2 & 0 & shear-out \\
\hline 60 & 2917 & 18225 & 4 & 0 & shear-out \\
\hline 61 & 2917 & 18225 & 6 & 0 & shear-out \\
\hline 62 & 2917 & 18225 & 8 & 0 & shear-out \\
\hline 63 & 2917 & 18225 & 9 & 0 & shear-out \\
\hline 69 & 3066 & 19155 & 2 & 0 & shear-out ultimate \\
\hline
\end{tabular}


Table 7 Progressive ply failure for bolt 3 in the three-bolt double-lap joint.

\begin{tabular}{|c|c|c|c|c|c|}
\hline $\begin{array}{c}\text { Load } \\
\text { increment }\end{array}$ & $\begin{array}{l}\text { Bolt load, } \\
\text { (lb) }\end{array}$ & $\begin{array}{l}\text { Applied joint } \\
\text { load, (lb) }\end{array}$ & $\begin{array}{c}\text { Ply } \\
\text { number }\end{array}$ & $\begin{array}{c}\text { Ply } \\
\text { orientation, } \\
\text { (degree) }\end{array}$ & Failure mode \\
\hline 1 & 2302 & 12769 & 11 & 90 & net-section \\
\hline 3 & 2325 & 12897 & 10 & 90 & net-section \\
\hline 6 & 2372 & 13156 & 19 & 0 & shear-out \\
\hline 8 & 2395 & 13288 & 17 & 0 & shear-out \\
\hline 10 & 2419 & 13420 & 15 & 0 & shear-out \\
\hline 11 & 2419 & 13420 & 20 & 45 & net-section \\
\hline 13 & 2443 & 13555 & 12 & 0 & shear-out \\
\hline 14 & 2443 & 13555 & 13 & 0 & shear-out \\
\hline 16 & 2468 & 13690 & 6 & 0 & shear-out \\
\hline 17 & 2468 & 13690 & 8 & 0 & shear-out \\
\hline 18 & 2468 & 13690 & 9 & 0 & shear-out \\
\hline 19 & 2468 & 13690 & 16 & 45 & net-section \\
\hline 21 & 2493 & 13827 & 2 & 0 & shear-out \\
\hline 22 & 2493 & 13827 & 4 & 0 & shear-out \\
\hline 24 & 2517 & 13965 & 1 & 45 & net-section \\
\hline 25 & 2517 & 13965 & 5 & 45 & net-section \\
\hline 26 & 2517 & 13965 & 5 & 45 & net-section ultimate \\
\hline 27 & 2517 & 13965 & 1 & 45 & net-section ultimate \\
\hline 28 & 2517 & 13965 & 3 & -45 & net-section \\
\hline 29 & 2517 & 13965 & 7 & -45 & net-section \\
\hline 30 & 2517 & 13965 & 10 & 90 & net-section ultimate \\
\hline 31 & 2517 & 13965 & 11 & 90 & net-section ultimate \\
\hline 32 & 2517 & 13965 & 14 & -45 & net-section \\
\hline 33 & 2517 & 13965 & 14 & -45 & net-section ultimate \\
\hline 34 & 2517 & 13965 & 2 & 0 & shear-out ultimate \\
\hline 35 & 2517 & 13965 & 3 & -45 & net-section ultimate \\
\hline 36 & 2517 & 13965 & 4 & 0 & shear-out ultimate \\
\hline 37 & 2517 & 13965 & 6 & 0 & shear-out ultimate \\
\hline 38 & 2517 & 13965 & 7 & -45 & net-section ultimate \\
\hline 39 & 2517 & 13965 & 8 & 0 & shear-out ultimate \\
\hline
\end{tabular}

An initial joint load of $P=312.5 \mathrm{lbs}$ is applied to the composite laminate while the end of the aluminum plate is constrained. Due to the presence of symmetry in geometry and loading, only the results concerning bolts 1 and 3 are presented. The maximum hole enlargement values associated with these bolt holes that were computed from the two-dimensional analysis are presented in Table 8 , and the spring stiffness values for each ply are in Table 9.

The through-the-thickness variation of the ply loads near bolt number 1 is shown in Fig. 20. The corresponding bolt/hole deformations are depicted in Fig. 21. As observed in these figures, the most pronounced deformation occurs in plies located along the plate interfaces.

As presented in Table 10, the initial ply failure near bolt 3 occurs at a load level of 14,507 lbs, in ply number 1 with a $45^{\circ}$ fiber orientation, in the netsection failure mode. The failure progresses with the $\pm 45^{\circ}$ and $90^{\circ}$ fiber orientations in the net-section mode, and further continues with the failure of plies with $0^{\circ}$ fiber orientation in the bearing mode. Part of the laminate near bolt 1 becomes unstable at load increment 50 , corresponding to a load of $18,790 \mathrm{lbs}$, in ply 7 with a $-45^{\circ}$ fiber orientation, in the netsection failure. At this load level, seven more failures occur in the composite laminate before the laminate is assumed to ultimately fail at load increment 71 , at a load level of 21,599 lbs. Near bolt 3, the initial ply initial failure occurs at $8,261 \mathrm{lbs}$, in ply 2 with $0^{\circ}$ fiber orientation, in the shear-out failure mode as presented in Table 11. The failure progresses with plies of $0^{0}$ fiber orientation in shear-out mode. Part of the laminate near bolt 3 becomes unstable at load increment 29, corresponding to a load of 9,401 lbs, in ply 3 with a $-45^{\circ}$ fiber orientation, in the net-section ultimate failure. At this load level, 11 more failures occur in the composite laminate before the laminate 
Table 8 Maximum hole enlargement in the fourbolt single-lap joint.

\begin{tabular}{|c|c|c|}
\hline & Bolt 1, (in) & Bolt 3, (in) \\
\hline $\begin{array}{c}\text { Aluminum } \\
\text { plate }\end{array}$ & $0.4144 \times 10^{-4}$ & $0.3169 \times 10^{-4}$ \\
\hline $\begin{array}{c}\text { Composite } \\
\text { plate }\end{array}$ & $0.8532 \times 10^{-4}$ & $1.4378 \times 10^{-4}$ \\
\hline
\end{tabular}

Table 9 Spring stiffness values in the four-bolt single-lap joint.

\begin{tabular}{|c|c|c|c|}
\hline \multicolumn{2}{|c|}{} & Bolt 1, (lb/in) & Bolt 3, (lb/in) \\
\hline \multicolumn{2}{|c|}{ Aluminum plate } & 39,527 & 63,183 \\
\hline \multirow{2}{*}{$\begin{array}{c}\text { Plies in } \\
\text { composite } \\
\text { plate }\end{array}$} & $45^{0}$ & 37,955 & 21,018 \\
\cline { 2 - 4 } & $0^{0}$ & 51,811 & 38,542 \\
\cline { 2 - 4 } & $-45^{0}$ & 34,835 & 29,017 \\
\cline { 2 - 4 } & $90^{0}$ & 8,747 & 6,516 \\
\hline
\end{tabular}

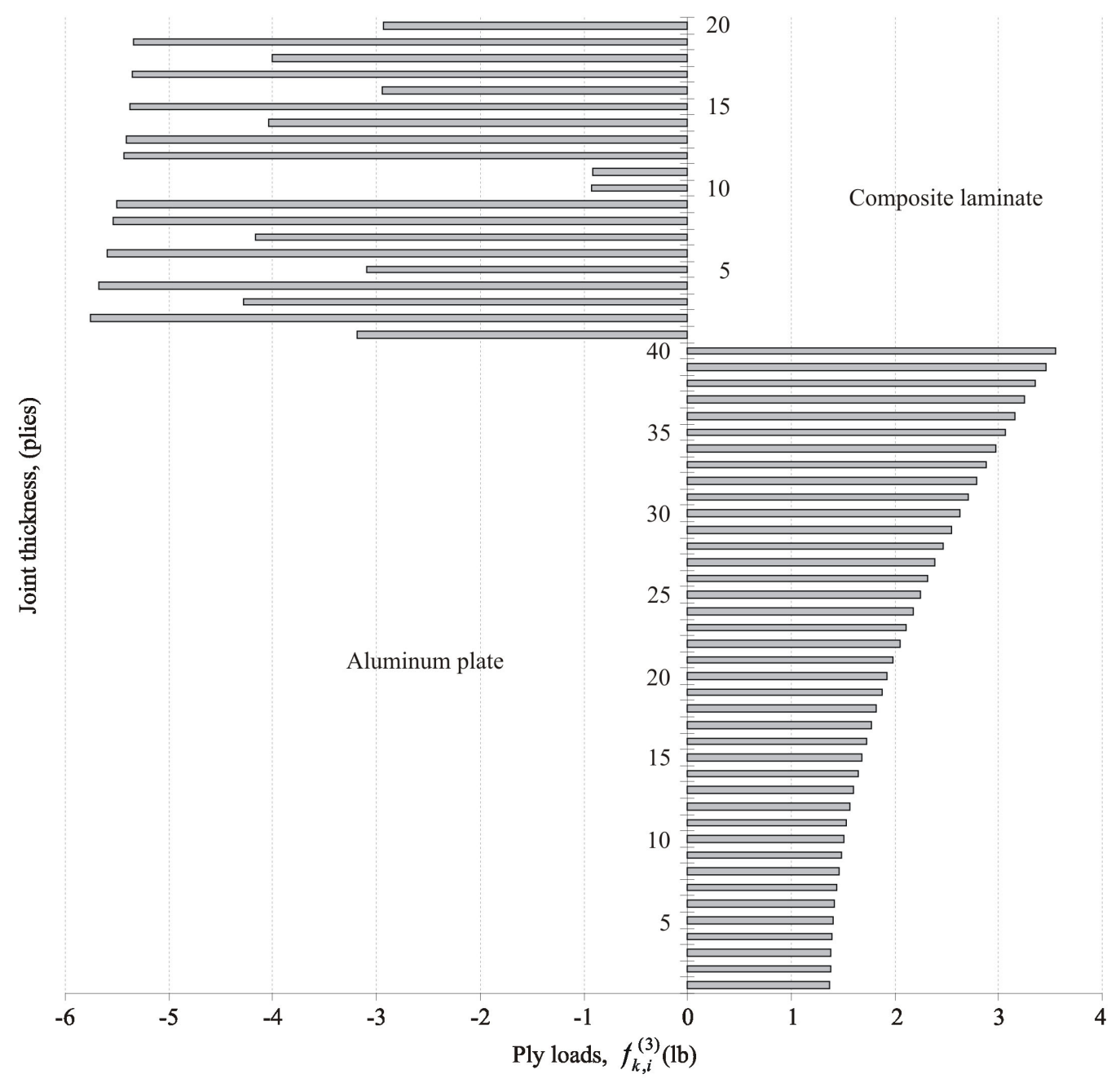

Fig. 20 Variation of ply loads through the joint thickness near bolt 3 in the four-bolt joint. 


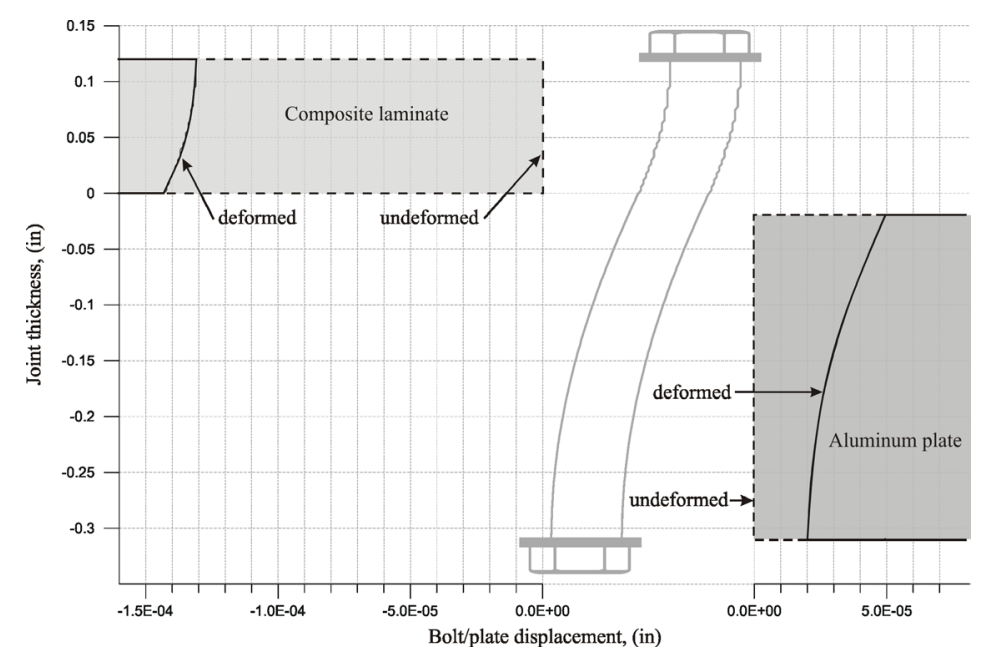

Fig. 21 Variation of bolt/plate displacement through the joint thickness near bolt 3 in the four-bolt joint.

Table 10 Progressive ply failure for bolt 1 in the four-bolt single-lap joint.

\begin{tabular}{|c|c|c|c|c|c|}
\hline $\begin{array}{c}\text { Load } \\
\text { increment }\end{array}$ & $\begin{array}{l}\text { Bolt load, } \\
\text { (lb) }\end{array}$ & $\begin{array}{l}\text { Applied joint } \\
\text { load, (lb) }\end{array}$ & $\begin{array}{c}\text { Ply } \\
\text { number }\end{array}$ & $\begin{array}{c}\text { Ply } \\
\text { orientation, } \\
\text { (degree) }\end{array}$ & Failure mode \\
\hline 1 & 3296 & 14507 & 1 & 45 & net-section \\
\hline 6 & 3430 & 15096 & 5 & 45 & net-section \\
\hline 14 & 3678 & 16185 & 16 & 45 & net-section \\
\hline 15 & 3678 & 16185 & 20 & 45 & net-section \\
\hline 20 & 3827 & 16842 & 10 & 90 & net-section \\
\hline 21 & 3827 & 16842 & 11 & 90 & net-section \\
\hline 24 & 3904 & 17181 & 1 & 45 & net-section ultimate \\
\hline 25 & 3904 & 17181 & 5 & 45 & net-section ultimate \\
\hline 26 & 3904 & 17181 & 10 & 90 & net-section ultimate \\
\hline 27 & 3904 & 17181 & 16 & 45 & net-section ultimate \\
\hline 28 & 3904 & 17181 & 11 & 90 & net-section ultimate \\
\hline 29 & 3904 & 17181 & 20 & 45 & net-section ultimate \\
\hline 32 & 3984 & 17526 & 2 & 0 & bearing \\
\hline 34 & 4022 & 17701 & 4 & 0 & bearing \\
\hline 37 & 4103 & 18057 & 6 & 0 & bearing \\
\hline 39 & 4144 & 18238 & 8 & 0 & bearing \\
\hline 40 & 4144 & 18238 & 9 & 0 & bearing \\
\hline 42 & 4185 & 18420 & 3 & -45 & net-section \\
\hline 43 & 4185 & 18420 & 12 & 0 & bearing \\
\hline 45 & 4227 & 18604 & 13 & 0 & bearing \\
\hline 46 & 4227 & 18604 & 15 & 0 & bearing \\
\hline 47 & 4227 & 18604 & 17 & 0 & bearing \\
\hline 48 & 4227 & 18604 & 19 & 0 & bearing \\
\hline 50 & 4270 & 18790 & 7 & -45 & net-section \\
\hline 51 & 4270 & 18790 & 7 & -45 & net-section ultimate \\
\hline 52 & 4270 & 18790 & 3 & -45 & net-section ultimate \\
\hline 53 & 4270 & 18790 & 14 & -45 & net-section \\
\hline 54 & 4270 & 18790 & 14 & -45 & net-section ultimate \\
\hline 55 & 4270 & 18790 & 18 & -45 & net-section \\
\hline 56 & 4270 & 18790 & 18 & -45 & net-section ultimate \\
\hline 71 & 4908 & 21599 & 2 & 0 & bearing ultimate \\
\hline
\end{tabular}


Table 11 Progressive ply failure for bolt 3 in the four-bolt single-lap joint.

\begin{tabular}{|c|c|c|c|c|c|}
\hline $\begin{array}{c}\text { Load } \\
\text { increment }\end{array}$ & $\begin{array}{l}\text { Bolt load, } \\
\text { (lb) }\end{array}$ & $\begin{array}{l}\text { Applied joint } \\
\text { load, (lb) }\end{array}$ & $\begin{array}{c}\text { Ply } \\
\text { number }\end{array}$ & $\begin{array}{c}\text { Ply } \\
\text { orientation, } \\
\text { (degree) }\end{array}$ & Failure mode \\
\hline 1 & 2260 & 8261 & 2 & 0 & shear-out \\
\hline 4 & 2305 & 8427 & 4 & 0 & shear-out \\
\hline 6 & 2329 & 8511 & 6 & 0 & shear-out \\
\hline 8 & 2352 & 8596 & 8 & 0 & shear-out \\
\hline 10 & 2375 & 8682 & 9 & 0 & shear-out \\
\hline 12 & 2399 & 8769 & 12 & 0 & shear-out \\
\hline 13 & 2399 & 8769 & 13 & 0 & shear-out \\
\hline 14 & 2399 & 8769 & 15 & 0 & shear-out \\
\hline 16 & 2423 & 8857 & 10 & 90 & net-section \\
\hline 17 & 2423 & 8857 & 17 & 0 & shear-out \\
\hline 18 & 2423 & 8857 & 19 & 0 & shear-out \\
\hline 20 & 2447 & 8945 & 11 & 90 & net-section \\
\hline 21 & 2447 & 8945 & 11 & 90 & net-section ultimate \\
\hline 25 & 2521 & 9216 & 3 & -45 & net-section \\
\hline 27 & 2547 & 9308 & 7 & -45 & net-section \\
\hline 29 & 2572 & 9402 & 3 & -45 & net-section ultimate \\
\hline 30 & 2572 & 9402 & 7 & -45 & net-section ultimate \\
\hline 31 & 2572 & 9402 & 10 & 90 & net-section ultimate \\
\hline 32 & 2572 & 9402 & 14 & -45 & net-section \\
\hline 33 & 2572 & 9402 & 14 & -45 & net-section ultimate \\
\hline 34 & 2572 & 9402 & 1 & 45 & net-section \\
\hline 35 & 2572 & 9402 & 1 & 45 & net-section ultimate \\
\hline 36 & 2572 & 9402 & 2 & 0 & shear-out ultimate \\
\hline 37 & 2572 & 9402 & 4 & 0 & shear-out ultimate \\
\hline 38 & 2572 & 9402 & 5 & 45 & net-section \\
\hline 39 & 2572 & 9402 & 5 & 45 & net-section ultimate \\
\hline 40 & 2572 & 9402 & 6 & 0 & shear-out ultimate \\
\hline 41 & 2572 & 9402 & 8 & 0 & shear-out ultimate \\
\hline
\end{tabular}

is assumed to ultimately fail at load increment 41 . Thus, the ultimate joint failure load occurs near bolt 3 at a load level of 9,402 lbs.

\section{Conclusions}

In this study, an approach to predict the strength of single- and double-lap bolted composites has been developed based on the through-the-thickness ply loads of the laminate in conjunction with the average stress failure criterion. This approach utilizes the model of a beam on an elastic foundation to compute the corrected ply loads utilizing a two- dimensional stress analysis based on the complex potential and variational formulation. In the case of a one-bolt single-lap aluminum-to-composite joint, the joint strength prediction from the present approach is in acceptable agreement with the experimental measurement published previously. This approach proves that the ply load distribution in a laminate is significantly influenced near the bolt by the bolt bending deforma- tions. This distribution is dependent on the plate thickness and laminate lay-up, and it is different for single- and double-lap bolted joints.

\section{References}

${ }^{1}$ Kradinov, V., Barut, A., Madenci, E., and Ambur, D. R., "Bolted Double-Lap Composite Joints Under Mechanical and Thermal Loading," International Journal of Solids and Structures, Vol. 38, 2001, pp. 57-75.

${ }^{2}$ Ramkumar, R. L., and Saether, E. S., "Strength Analysis of Composite and Metallic Plates Bolted Together by a Single Fastener," Aircraft Division, Report AFWAL-TR-85-3064, Northrop Corporation, Hawthorne, CA, August 1985.

${ }^{3}$ Whitney, J. M. and Nuismer, R. J., "Stress Fracture Criteria for Laminated Composites Containing Stress Concentrations," Journal of Composite Materials, Vol. 8, 1974, pp. 253-265. 
${ }^{4}$ Kradinov, V., Madenci, E., and Ambur, D. R., "Analysis of Bolted Laminates of Varying Thickness and Lay-up with Metallic Inserts," AIAA Paper 2003-1998, April 2003.

${ }^{5}$ Eriksson, I., Backlund, J., and Moller, P., "Design of Multiple-Row Bolted Composite Joints Under General In-Plane Loading," Composites Engineering, Vol.5, 1995, pp. 1051-1068.
${ }^{6}$ Xiong Y., “An Analytical Method for Failure Pre diction of Multi-Fastener Composite Joints," International Journal of Solids and Structures, Vol. 33, 1995, pp. 4395-4409.

${ }^{7}$ Ghali, A., and Neville, A. M., Structural Analysis: A Unified Classical and Matrix Approach, Chapman and Hall, New York, 1978.

\section{Appendix}

In the $k^{\text {th }}$ laminate, the strain energy of the $l^{\text {th }}$ bolt, which is defined by a uniform cross-section, $A^{(\ell)}$, moment of inertia, $I^{(\ell)}$, and Young's and shear moduli, $E^{(\ell)}$ and $G^{(\ell)}$, respectively, can be expressed as

$$
B_{k}^{(\ell)}=\sum_{i=1}^{K-1} \frac{1}{2} \mathbf{q}_{k}^{(i \ell) T} \mathbf{b}_{k}^{(i \ell)} \mathbf{q}_{k}^{(i \ell)}
$$

where $\mathbf{q}_{k}^{(i \ell)}$ represents the vector of nodal deflections and rotations for the $i^{\text {th }}$ beam element and $K$ is the number of nodes in the bolt discretization. The stiffness matrix for a two-node Timoshenko beam element is given by Ghali and Neville ${ }^{7}$ as

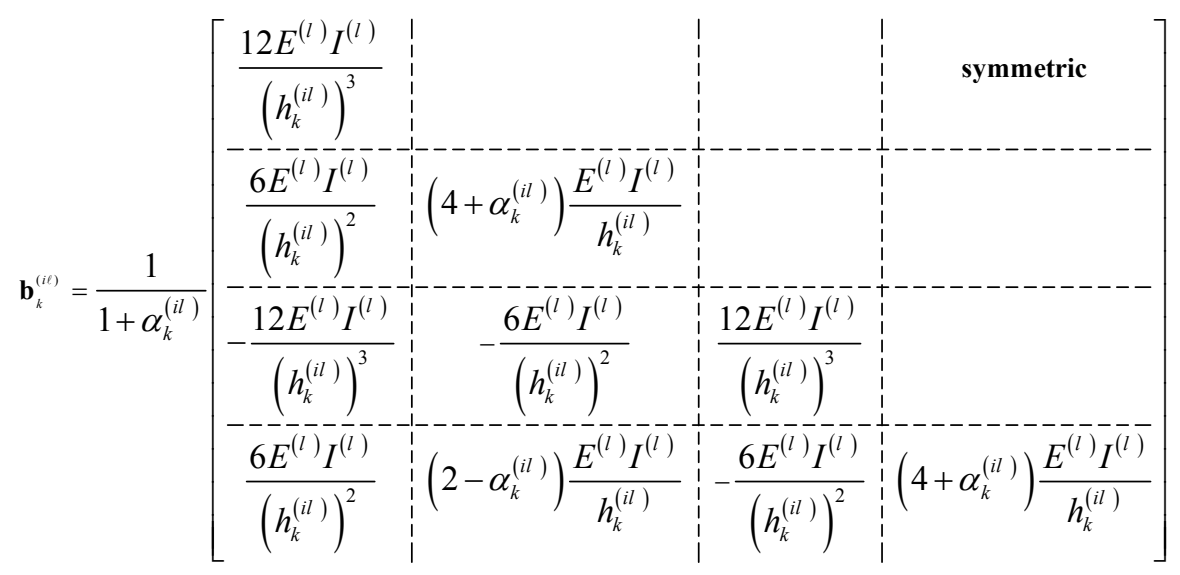

where $\alpha_{k}^{(i \ell)}=\left(h_{k}^{(i \ell)}\right)^{2} G^{(\ell)} A^{(\ell)} / 12 E^{(\ell)} I^{(\ell)} c$ in which $c$ represents the shear correction factor.

Rearranging the right-hand side of Eq. (A1) such that the matrices are suitable for static condensation of the internal nodal rotations leads to

$$
B_{k}^{(\ell)}=\frac{1}{2}\left\{\begin{array}{c}
\Delta_{k}^{(\ell)} \\
\mathbf{q}_{k, \phi}^{(\ell)}
\end{array}\right\}^{T}\left[\begin{array}{ll}
\mathbf{b}_{k, \Delta \Lambda}^{(\ell)} & \mathbf{b}_{k, \Delta \phi}^{(\ell)} \\
\mathbf{b}_{k, \Delta \phi}^{(\ell)} & \mathbf{b}_{k, \phi \phi}^{(\ell)}
\end{array}\right]\left\{\begin{array}{c}
\Delta_{k}^{(\ell)} \\
\mathbf{q}_{k, \phi}^{(\ell)}
\end{array}\right\}
$$

where

$$
\begin{aligned}
& \Delta_{k}^{(\ell)^{T}}=\left\{\begin{array}{llllllll}
\Delta_{k, 1}^{(\ell)} & \phi_{k, 1}^{(\ell)} & \Delta_{k, 2}^{(\ell)} & \Delta_{k, 3}^{(\ell)} & \cdots & \Delta_{k, K-1}^{(\ell)} & \Delta_{k, K}^{(\ell)} & \phi_{k, K}^{(\ell)}
\end{array}\right\} \\
& \mathbf{q}_{k, \phi}^{(\ell)}=\left\{\begin{array}{lllll}
\phi_{k, 2}^{(\ell)} & \phi_{k, 3}^{(\ell)} & \cdots & \phi_{k,(K-1)}^{(\ell)}
\end{array}\right\}
\end{aligned}
$$




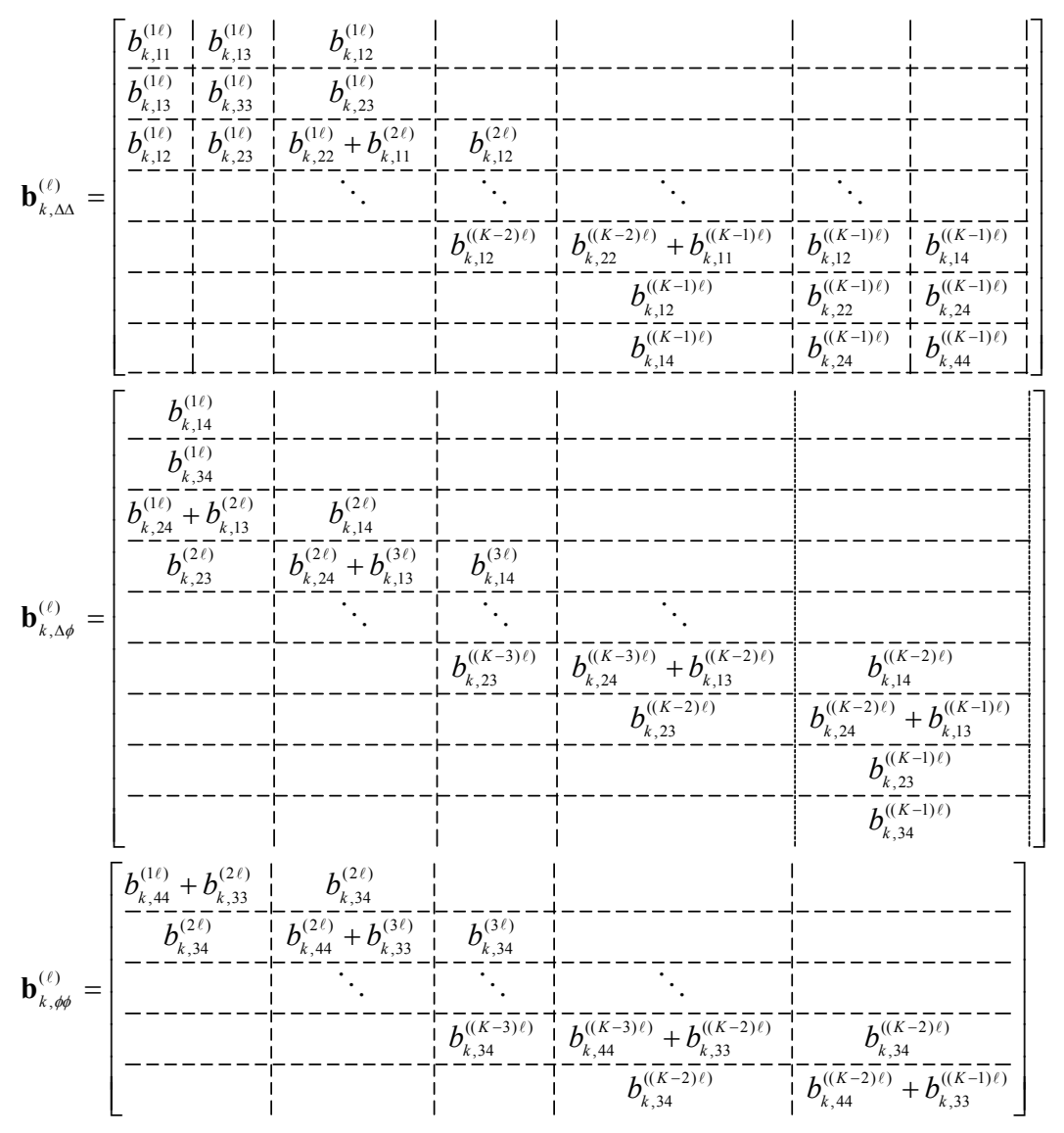

(A5)

Since the internal nodes are not subjected to external moments, the first variation of the strain energy with respect to the vector $\mathbf{q}_{k, \phi}^{(\ell)}$ vanishes, resulting in the moment equilibrium equations as

$$
\mathbf{b}_{k, \Delta \phi}^{(\ell) T} \Delta_{k}^{(\ell)}+\mathbf{b}_{k, \phi \phi}^{(\ell)} \mathbf{q}_{k, \phi}^{(\ell)}=\mathbf{0}
$$

Solving for $\mathbf{q}_{k, \phi}^{(\ell)}$ in the Eq. (A8) and substituting into Eq. (A3), after rearranging the terms, leads to

$$
B_{k}^{(e)}=\frac{1}{2} \boldsymbol{\Delta}_{k}^{(\ell) T} \mathbf{b}_{k}^{(\ell)} \boldsymbol{\Delta}_{k}^{(\ell)}
$$

where the matrix $\mathbf{b}_{k}^{(t)}$ is defined as

$$
\mathbf{b}_{k}^{(\ell)}=\mathbf{b}_{k, \Delta \Delta}^{(\ell)}-\frac{1}{2} \mathbf{b}_{k, \Delta \phi}^{(\ell)}{ }^{T} \mathbf{b}_{k, \phi \phi}^{(\ell)-1} \mathbf{b}_{k, \Delta \phi}^{(\ell)}
$$

The strain energy of the translational and rotational spring elements can be expressed as

$$
S_{k}^{(\ell)}=\frac{1}{2} \bar{\Delta}_{k}^{(\ell) T} \overline{\boldsymbol{k}}_{k}^{(\ell)} \bar{\Delta}_{k}^{(\ell)}
$$

in which $\overline{\boldsymbol{\Delta}}_{k}^{(1)}$ is the same as $\boldsymbol{\Delta}_{k}^{(i)}$ with an additional degree of freedom representing the rigid base for the springs, and $\overline{\boldsymbol{k}}_{k}^{(\text {()) }}$ is defined as 


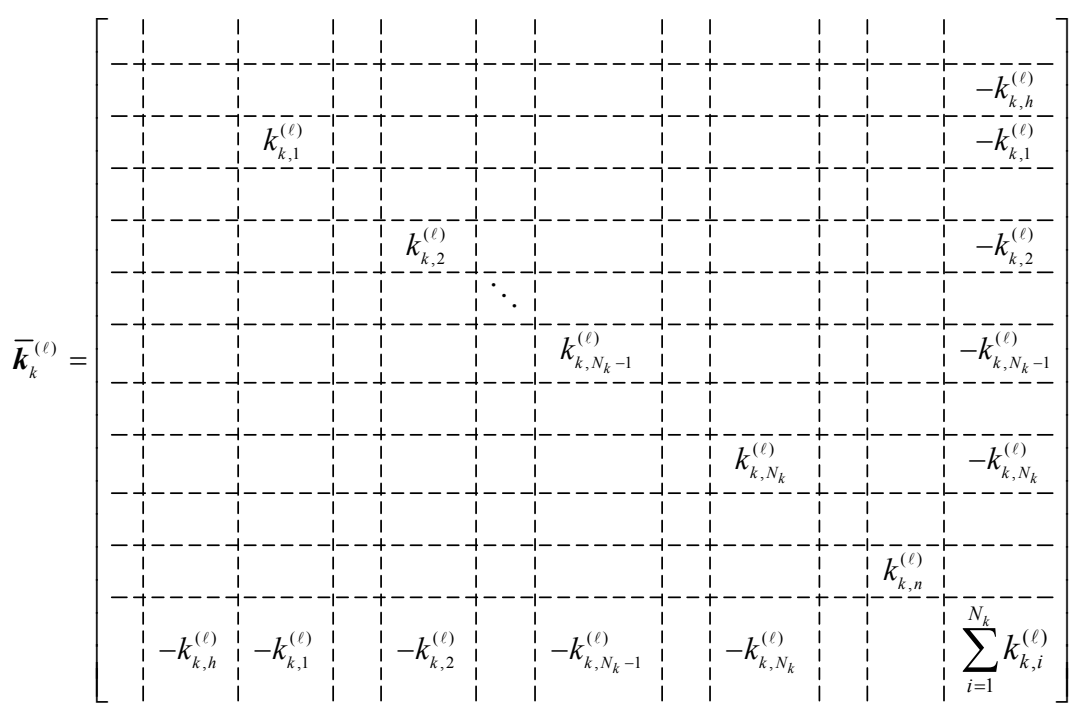

(A12)

where the last column and row appear due to degrees of freedom associated with the rigid base. Since the rigid base is fixed, this column and row are eliminated from the matrix in Eq. (A12). Thus, the total strain energy of the beam on an elastic foundation can be written as

$$
U_{k}^{(\ell)}=B_{k}^{(\ell)}+S_{k}^{(\ell)}
$$

or

$$
U_{k}^{(\ell)}=\frac{1}{2} \boldsymbol{\Delta}_{k}^{(\ell) T}\left(\mathbf{b}_{k}^{(\ell)}+\boldsymbol{k}_{k}^{(\ell)}\right) \boldsymbol{\Delta}_{k}^{(\ell)}
$$

in which $\boldsymbol{k}_{k}^{(\ell)}$ is defined by

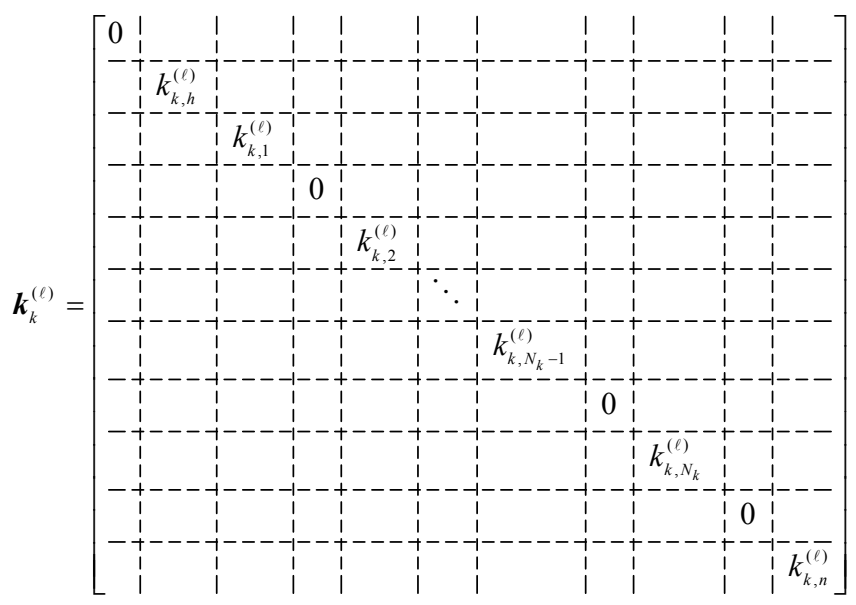

In the case of a single-lap bolted joint, the bolt nut is not present in the top plate, $k=1$, while the bolt head is not present in the bottom plate, $k=2$; thus, $k_{1, n}^{(\ell)}=0$ in the top plate and $k_{2, h}^{(\ell)}=0$ in the bottom plate. In the absence of both head and nut in the middle plate of a double-lap bolted joint, in addition to the values of $k_{1, n}^{(\ell)}=k_{3, h}^{(\ell)}=0$ for the top and bottom plates, $k_{2, h}^{(\ell)}=k_{2, n}^{(\ell)}=0$ in the middle plate. 
The total potential energy of the $\ell^{\text {th }}$ bolt can be expressed as

$$
\pi=U^{(\ell)}-W^{(\ell)}=\frac{1}{2} \boldsymbol{\Delta}^{(\ell) T} \mathbf{K}^{(\ell)} \boldsymbol{\Delta}^{(\ell)}-\mathbf{F} \boldsymbol{\Delta}^{(\ell)}
$$

where

$$
\mathbf{K}^{(\ell)}=\left[\begin{array}{cc}
\mathbf{b}_{1}^{(\ell)}+\mathbf{k}_{1}^{(\ell)} & \mathbf{0} \\
\mathbf{0} & \mathbf{b}_{2}^{(\ell)}+\mathbf{k}_{2}^{(\ell)}
\end{array}\right], \quad \mathbf{F}=\left[\begin{array}{c}
0 \\
\vdots \\
0 \\
P_{1}^{(\ell)} \\
P_{2}^{(\ell)} \\
0 \\
\vdots \\
0
\end{array}\right] \operatorname{node} K
$$

and

$$
\Delta^{(\ell) T}=\left\{\begin{array}{llllll}
\Delta_{1}^{(\ell)} & \phi_{1}^{(\ell)} & \Delta_{2}^{(\ell)} & \cdots & \Delta_{K+M}^{(\ell)} & \phi_{K+M}^{(())}
\end{array}\right\}
$$

for a single-lap joint, and

$$
\mathbf{K}^{(\ell)}=\left[\begin{array}{ccc}
\mathbf{b}_{1}^{(t)}+\mathbf{k}_{1}^{(\ell)} & \mathbf{0} & \mathbf{0} \\
\mathbf{0} & \mathbf{b}_{2}^{(\ell)}+\mathbf{k}_{2}^{(\ell)} & \mathbf{0} \\
\mathbf{0} & \mathbf{0} & \mathbf{b}_{3}^{(\ell)}+\mathbf{k}_{3}^{(\ell)}
\end{array}\right], \quad \mathbf{F}=\left[\begin{array}{c}
0 \\
\vdots \\
0 \\
P_{1}^{(\ell)} \\
-P_{1}^{(\ell)} \\
0 \\
\vdots \\
0 \\
\\
\end{array}\right.
$$

and

$$
\Delta^{(\theta) T}=\left\{\begin{array}{lllllllll}
\Delta_{1}^{(\ell)} & \phi_{1}^{(\ell)} & \Delta_{2}^{(\ell)} & \cdots & \Delta_{K+M}^{(())} & \phi_{K+M}^{(\ell)} & \cdots & \Delta_{K+M+P}^{(())} & \phi_{K+M+P}^{(\ell)}
\end{array}\right\}
$$

for a double-lap joint. The variables $K, M$, and $P$ define the number of nodes in the beam discretization for each plate.

According to the bilinear behavior of the ply loads shown in Fig. 10, the coefficients of the matrix $\boldsymbol{k}_{k}^{(\ell)}$ become $\hat{k}_{k, i}^{(\ell)}\left[\hat{k}_{k, i}^{(\ell)}=\alpha k_{k, i}^{(\ell)}\right.$, where $\left.\alpha=0.1\right]$ for initially damaged plies and zero for totally damaged plies. Also, for initially damaged plies, the values of $\left(k_{k, i}^{(\ell)}-\hat{k}_{k, i}^{(\ell)}\right) \Delta_{k, j}^{(\ell) I N}$ are added to the corresponding locations in the vector of externally applied loads, $\mathbf{F}$.

Appling the principle of minimum potential energy and forcing the first variation of the total potential to vanish, $\delta \pi=0$, leads to the system of equilibrium equations 
In the finite element formulation of the problem, additional constraint equations are introduced to ensure the continuity of the rotational degree of freedom between the adjacent section of the beam

$$
\begin{aligned}
& \phi_{K}^{(1)}=\phi_{K+1}^{(())} \quad \text { for a single lap joint } \\
& \left\{\begin{array}{l}
\phi_{K}^{(())}=\phi_{K+1}^{(())} \\
\phi_{K+M}^{(()}=\phi_{K+M+1}^{(1)}
\end{array} \quad\right. \text { for a double lap joint }
\end{aligned}
$$

These constraint conditions are enforced by adding an additional row and column with all but two elements set to zero in the matrix $\mathbf{K}^{(\ell)}$. Two nonzero elements are set to 1 and -1 in the locations corresponding to the nodal rotations; a zero value is added in the right-hand side.

\# 